\title{
Geomagnetic storm effects in the low- to middle-latitude upper thermosphere
}

\author{
A. G. Burns, T. L. Killeen, W. Deng, ${ }^{1}$ and G. R. Carignan \\ Space Physics Research Laboratory, Department of Atmospheric, Oceanic and Space Science, University of \\ Michigan, Ann Arbor
}

R. G. Roble

High Altitude Observatory, National Center for Atmospheric Research, Boulder, Colorado

\begin{abstract}
In this paper, we use data from the Dynamics Explorer 2 (DE 2) satellite and a theoretical simulation made by using the National Center for Atmospheric Research thermosphere/ionosphere general circulation model (NCAR-TIGCM) to study storm-induced changes in the structure of the upper thermosphere in the low- to middle-latitude $\left(20^{\circ}-40^{\circ} \mathrm{N}\right)$ region of the winter hemisphere. Our principal results are as follows: (1) The winds associated with the diurnal tide weaken during geomagnetic storms, causing primarily zonally oriented changes in the evening sector, few changes in the middle of the afternoon, a combination of zonal and meridional changes in the late morning region, and mainly meridional changes early in the morning. (2) Decreases in the magnitudes of the horizontal winds associated with the diurnal tide lead to a net downward tendency in the vertical winds blowing through a constant pressure surface. (3) Because of these changes in the vertical wind, there is an increase in compressional heating (or a decrease in cooling through expansion), and thus temperatures in the low- to middle-latitudes of the winter hemisphere increase. (4) Densities of all neutral species increase on a constant height surface, but the pattern of changes in the $\mathrm{O} / \mathrm{N}_{2}$ ratio is not well ordered on these surfaces. (5) The pattern of changes in the $\mathrm{O} / \mathrm{N}_{2}$ ratio is better ordered on constant pressure surfaces. The increases in this ratio on constant pressure surfaces in the low-to middle-latitude, winter hemisphere are caused by a more downward tendency in the vertical winds that blow through the constant pressure surfaces. Nitrogen-poor air is then advected downward through the pressure surface, increasing the $\mathrm{O} / \mathrm{N}_{2}$ ratio. (6) The daytime geographical distribution of the modeled increases in the $\mathrm{O} / \mathrm{N}_{2}$ ratio on a constant pressure surface in the low-to middle-latitudes of the winter hemisphere correspond very closely with those of increases in the modeled electron densities at the $F_{2}$ peak.
\end{abstract}

\section{Introduction}

Over the years the effects of geomagnetic storms on the ionosphere/thermosphere system have attracted much interest. Appleton and Ingram [1935] noted that $f_{0} F_{2}$ (the maximum frequency at the $F_{2}$ peak) decreased significantly at middle latitudes during ionospheric storms. Seaton [1956] first suggested that these reductions might be tied to thermospheric neutral composition, and Duncan [1969] put this hypothesis on a more rigorous basis. Since that time a large effort has gone into studying these types of changes in the middle- and high-latitude neutral thermosphere and their effects on the ionosphere. These studies have now reached sufficient maturity that the major processes that drive changes in the middle- and high-latitude upper thermospheric composition during geomagnetic storms can be described with some confidence.

\footnotetext{
${ }^{1}$ Now at Haystack Observatory, Massachusetts Institute of Technology, Westford.
}

Copyright 1995 by the American Geophysical Union.

Paper number 94JA03232. $0148-0227 / 95 / 94 \mathrm{JA}-03232 \$ 05.00$
At the beginning of a geomagnetic storm, high-latitude magnetospheric potentials increase. Field-aligned currents connect the magnetospheric electric field with the ionosphere, where it drives ions much faster than normal. These ions collide with the neutral gas increasing neutral wind speed and driving intense Joule heating. This heating causes an initial upwelling around the auroral oval which generates a large wave that can propagate to the equator in a few hours [e.g., Mayr et al., 1984; Prölss, 1993; and the references therein]. Meanwhile, Joule heating, which is still strong in the highlatitude regions, continues to cause strong upward winds that transport nitrogen-rich air up from much lower in the thermosphere into the $F$ region [e.g., Prölss, 1980; Mayr et al., 1978]. Neutral winds then redistribute this nitrogen-rich air over much of the high-latitude region and part of the middle-latitude region. The primary mechanism that drives these horizontal winds is not the pressure gradient force, as originally thought, but rather the strong ion-neutral coupling in the polar cap region [Burns et al., 1991]. This last point is important in determining the pattern of the resultant region of nitrogen-rich air. Instead of being fairly isotropically distributed about the auroral oval, as pressure gradient forces would imply, the pattern has a pronounced tail that starts near local magnetic midnight and extends toward dawn [e.g., Prölss, 1981; 1993]. 
Less is known about storm-induced temperature changes, even at high latitudes. No detailed morphology of the temperature, such as that described for composition by Prölss [1981], existed until recently [Burns et al., 1992b]. Many processes can affect high-latitude storm time heating and cooling, so a complex temperature morphology occurs, with the highest temperature increases normally being found immediately around the auroral oval.

High-latitude geomagnetic-storm-induced wind changes have been studied in some detail in the last decade. Killeen et al. [1984] looked at the neutral winds during some storm-time orbits and McCormac et al. [1987] developed an overall morphology for these high-latitude winds during active geomagnetic conditions. Forbes et al. [1987] made comparisons between the then named National Center for Atmospheric Research thermospheric general circulation model (NCAR-TGCM) and cross-track winds measured by the satellite electrostatic triaxial accelerometer (SETA) instrument, and found poor agreement between modeled winds and data. However, refinements to the model since that time give a much more accurate representation of storm time neutral winds [e.g., Deng et al., 1993].

The situation is even more complicated at lower latitudes. Over the years, many observations have indicated that large changes occur throughout the upper thermosphere, even near the equator. Confusion reigns over whether these changes include neutral composition changes and, if they do, what they are. Satellite data have indicated that the densities of all species increase at low and low-middle latitudes during geomagnetic storms [e.g., Mayr et al., 1978; Hedin et al., 1977; Prölss et al., 1988; and the references therein], but that large changes in neutral composition do not occur along a satellite track [Prölss, 1987]. However, both major thermospheric general circulation models predict that such changes in composition do occur [e.g., see Rishbeth et al., 1987; Crowley et al., 1989; Fuller-Rowell et al., 1991; 1994]. Among other work, in this paper we reconcile observations of neutral composition with model output and describe a mechanism that explains these changes. An important difference between the models and the observations is that the models use constant pressure surfaces, whereas the data are measured at sets of constant heights along satellite orbits. This difference has yet to be explored fully, but Prölss [1987] showed that when gas densities in storm times were compared with gas densities in quiet times, the low- and low- to middlelatitude neutral composition changes seen on constant pressure surfaces were different from those seen on constant height surfaces. In his study, Prölss compared data for constant height surfaces with data for constant pressure surfaces and showed that for the orbit considered, low- and low- to middle-latitude changes in the $\mathrm{N}_{2} / \mathrm{O}$ ratio were positive but of small magnitude on constant height surfaces and negative but of small magnitude on constant pressure surfaces. However, because he used the $\mathrm{N}_{2} / \mathrm{O}$ ratio rather than the $\mathrm{O} / \mathrm{N}_{2}$ ratio, he concluded that the ratio was only moderately affected by the coordinate transformation. As we will show later, the differences seen when using the $\mathrm{O} / \mathrm{N}_{2}$ ratio can be quite pronounced (a $\sim 50 \%$ increase at least) during large disturbances, and this has the potential to affect electron densities.

A number of observers have noted that temperature changes also occur at low and low-middle latitudes during geomagnetic storms. Biondi and Sipler [1985] and Biondi and Meriwether
[1985] looked at the temperature changes that occurred at equatorial latitudes and saw nighttime temperature enhancements during geomagnetic storms. Various other authors have also made observations of low- and low- to middle-latitude temperature enhancements during geomagnetic storms and have seen enhancements of $50 \mathrm{~K}$ [Taeusch et al., 1971; Blamont and Luton, 1972] and from 100 to $200 \mathrm{~K}$ [Chandra and Spencer, 1976; Nisbet et al., 1977].

Electron density changes at low and low-middle latitudes are not the main focus of this paper, but previous discussions of their changes in response to geomagnetic forcing are relevant to this work, because the importance of feedback processes indicates that the thermosphere-ionosphere system cannot be separated into independent parts in any meaningful way. Thus low- and low- to middle-latitude increases in electron densities, if correctly interpreted, can give an indication of what is happening in the thermosphere. Studies of these increases have a long history. Berkner et al. [1939] and Berkner and Seaton [1940] noticed that low- and low- to middle-latitude enhancements of electron density occurred during geomagnetic storms. More recent studies have stressed their morphological aspects and have considered mechanisms by which they can occur [e.g., Rishbeth, 1986; Forbes, 1989; Prölss et al., 1991; Mendillo et al., 1992). At the same time that these "positive storm effects" occur, the height of the $F_{2}$ layer rises [e.g., Prölss et al., 1991]. This rise in altitude is accompanied by an increase in the thickness of the $F_{2}$ layer and an increase in total electron content [e.g., Hargreaves and Bagenal, 1977; Buonsanto et al., 1979; Jakowski et al., 1990]. Furthermore, Rishbeth and Edwards [1989, 1990] have shown that the height of the $F_{2}$ peak is ordered better in pressure coordinates than it is in altitude coordinates for a variety of different geophysical conditions at a particular local time. They have also stated [Rishbeth and Edwards, 1990] that composition changes could explain the annual variation in the pressure height at which the $F_{2}$ peak occurs for Slough, but not for lower latitudes. Mendillo et al. [1992] used the MSIS model to gain an idea of the effects of changing pressure surfaces on the ionosphere, using the same concept of reduced height as Rishbeth et al. [1978] had detailed in their $F_{2}$ layer servo model.

Various explanations for positive storm effects at low and low-middle latitudes exist; Prölss et al. [1991] have discussed these explanations. For example, heating in the auroral oval generates a large wave early in the storm. This wave propagates to the equator, potentially generating both positive and negative storm effects. However, these shortterm, wave-induced changes are not a focus of this work. Instead, we look at long-duration positive storm effects at low-middle (for the purposes of this paper defined as being latitudes between $20^{\circ}$ and $40^{\circ} \mathrm{deg}$. in the winter hemisphere) latitudes. Prölss et al. [1991] discussed some explanations for these effects: first, that changes in the meridional circulation could lift the ionization maximum up into regions where neutral composition was different and thus where recombination of ions with electrons was slower; and second that the neutral composition changes, so that the recombination rate is again slower. Their conclusion was that the first of these two mechanisms was the more likely one. A third explanation involves electric fields [e.g., Forbes, 1989], and a fourth involves particle precipitation [e.g., Prölss et al., 1991]. 
It has been difficult to evaluate the relative merit of these explanations because of a lack of hard evidence upon which to base a decision. For example, ground-based optical instruments only make measurements during the night, so neutral wind and temperature data are lacking during the daylight hours. Also, the distribution of these stations, which tend to be located at high and high-middle geomagnetic latitudes, is not ideal for observing low- and low- to middlelatitude phenomena, such as these changes in the circulation and temperature structure. Satellite data are available, but the problem of storm-related wind and temperature changes at low and low-middle latitudes has not been studied in much detail (however, see Burns and Killeen [1992 a, b]; and Burrage et al. [1992]). More attention has been paid to compositional changes [e.g., Prölss, 1987; Prölss et al., 1988], but there are problems with the interpretation of these compositional changes that will become apparent later in this paper. While incoherent scatter radar data do provide neutral wind estimations, these estimations are partially based on empirical models, which may not be completely valid in the rapidly changing conditions associated with geomagnetic storms. Furthermore, incoherent scatter radars are expensive to build and run, so there are very few of them. Ionosondederived winds provide good geographic coverage, but the analysis of these data is dependent on the assumption that neutral wind changes drive ionospheric changes. Thus they do not provide an unambiguous description of the changes in the neutral winds that occur during geomagnetic storms.

In this paper, we use satellite-derived temperature and wind data to study the longer-term circulation and wind changes that are induced by geomagnetic storms, and then we extend this analysis to examine their effect on neutral composition and their potential effect on electron densities. Recently, FullerRowell et al. [1994] looked at the problem of the changes that occur in the thermosphere as a result of geomagnetic storms using the coupled thermosphere ionosphere model (CTIM). They found that there were longer-term circulation changes that resulted in thermospheric heating and neutral composition changes. In this paper we have not only used a theoretical model to predict the changes that occurred, but also applied the diagnostic package of Killeen and Roble [1984] to provide an analytical analysis of why the changes are occurring, and for the first time, we have provided a coherent set of experimental data that help to support the NCAR thermosphere/ionosphere general circulation model (NCARTIGCM) predictions of the changes that occur in the low- to middle-latitude thermosphere as a result of geomagnetic storms.

Before presenting this analysis, we discuss the model run and the data used in section 2 . Section 3 includes a discussion of storm-induced changes in the tidal winds and the causes of these changes. These circulation changes cause temperature changes: we discuss these changes and their cause in section 4 . In turn the thermal and circulation changes cause changes in neutral composition (section 5). Furthermore, the neutral thermosphere has the potential to affect the ionosphere strongly at this time; we present a simulation of these changes in section 6 . The results of this paper are discussed in section 7. Finally, this work is summed up in the last section.

\section{Model and Data Considerations}

The DE 2 satellite [Hoffman et al., 1981] flew between July 1981 and February 1983. Among the many instruments on board this satellite was the wind and temperature spectrometer (WATS) [Spencer et al., 1981], which measured thermospheric neutral temperatures and one component of the neutral wind. The Fabry-Perot interferometer [Hays et al., 1981] measured the other component of the neutral wind, permitting some measurements of geomagnetic-storm-induced neutral wind changes in the daytime at low-middle latitudes. We use these measurements here to study storm-induced changes in the neutral winds and temperatures of the upper thermosphere.

In addition, we use neutral composition data from the neutral atmosphere composition spectrometer (NACS) instrument [Carignan et al, 1981] to illustrate the effects of these changes in circulation and temperature on the dayside composition. Comparisons between these DE 2 data and the NCAR-TIGCM can then give us confidence that the model predictions of the observed changes are accurate, allowing us to interrogate the model further, both to understand the causes of these changes better and to examine some of their consequences.

The NCAR-TIGCM is a three-dimensional, timedependent model of the Earth's neutral upper atmosphere that is run on the CRAY-YMP computer at NCAR. The model uses a finite-differencing technique to obtain time-dependent solutions for the coupled, nonlinear equations of hydrodynamics, thermodynamics, and continuity of the neutral gas [Dickinson et al., 1981; Roble et al., 1982] and for the coupling between the dynamics and the composition [Dickinson et al., 1984]. A TIGCM, with a coupled ionosphere and a self-consistent aeronomic scheme, was developed by Roble et al. [1988]. More recently, the model has been improved by including a self-consistent dynamo model [Richmond et al., 1992]. The latest developments in this suite of models include coupling with the stratosphere and mesosphere [Roble and Ridley, 1994]. Detailed descriptions of the NCAR models, as well as their input parameterizations, have been given previously in papers by Dickinson et al. [1981, 1984], Roble et al. [1982, 1987a, 1988], Richmond et al. [1992], and Roble and Ridley [1994]. In this paper we use the thermosphere/ionosphere version of the model (TIGCM).

Various publications have discussed the use of both the NCAR-TIGCM that is described above and the University College London-thermospheric general circulation model (UCL-TGCM) [Fuller-Rowell and Rees, 1980, 1983; FullerRowell et al., 1987] to understand geomagnetic-storm-induced changes in the thermosphere [e.g., Fuller-Rowell and Rees, 1981; Rishbeth et al., 1985, 1987; Roble et al., 1987b; Forbes et al., 1987; Crowley et al., 1989; Fuller-Rowell et al., 1989, 1991, 1994; Burns et al., 1991, 1992a, b; Deng et al., $1991,1993)$. Over the last 15 years this work and many datarelated and other modeling studies have vastly increased our knowledge of the behavior of the thermosphere during geomagnetic storms, allowing us to describe the causes of most of the major changes seen at high latitudes (see the introduction for a brief summary of these processes).

One of these aforementioned studies was that by Deng et al. [1993]. Deng et al. [1993] modeled two storms, the second of which is the main simulation used in this paper. This small storm had two pulses which occurred on December 7 and 8 , 1982, respectively. Prölss et al. [1991] discussed its ionospheric signature, using ionosondes from a number of locations spread around the globe. Clear examples of signatures of long-term positive storm effects exist, 
permitting the use of this period as an indicator of the normal behavior of the low- to middle-latitude winter ionosphere during "normal" small geomagnetic storms. Figure 1 shows variations in the auroral electrojet index $(A E)$ and $K p . K p$ reached its highest values on the December 7 , the first day of the storm, when it reached $6+$. On the second day the largest $K p$ values were 5-, not really large enough to be classified as a storm. In contrast to this, $A E$ values were higher on December 8 than they were on December 7. They reached values of 1500 $\mathrm{nT}$ on December 8 and remained above $800 \mathrm{nT}$ for about 8 hours. On December 7, maximum values of $A E$ were about $1200 \mathrm{nT}$, and sustained values above $500 \mathrm{nT}$ only occurred during two 1 - to 2 -hour periods. So, despite the smaller values of $K p$ on December 8, the $A E$ indices indicate that storm conditions were occurring on this day. Further support for the idea that storm conditions were occurring on this day is given by the observation that large neutral winds occurred across the polar cap.

These indices were not used to run the TIGCM. Instead, interplanetary magnetic field and solar wind data were processed by using formulae given by Reiff et al. [1985], Reiff and Luhmann [1986], and B. A. Emery (private communication, 1992) to obtain values for the hemispheric power and cross-cap potential. The TIGCM was then run using these inputs and the $\mathrm{Y}$ component of the IMF.

Data from several other storms are used in this paper. A large geomagnetic storm occurred on March 2, 1982. It commenced in the middle of March 1 , and $K p$ exceeded 8 for 6 hours at the beginning of March 2. Values of $K p$ were greater than 6 for 15 hours on March 2. A much smaller storm occurred on March 22, 1982. During a total time when $K p$ exceeded 5 for 9 hours, it exceeded 6 for 6 hours. One of the largest storms of the entire period when DE 2 was flying occurred on September 5 and 6, 1982. This geomagnetic storm commenced on September 5 and continued on September 6. Large values of $K p$ occurred for a considerable period on September 6: $K p$ exceeded 8 for 15 hours on this day. Another very large storm occurred on November 24, 1982. This storm is discussed in detail in Burns et al. [1992b] and Deng et al. [1993]. Although the $K p$ trace does not indicate that any storm activity was occurring on December 16,1982, the $A E$ index suggests otherwise. Values of $A E$ of $750 \mathrm{nT}$ and above had been occurring for some hours before orbit 7561 took place.

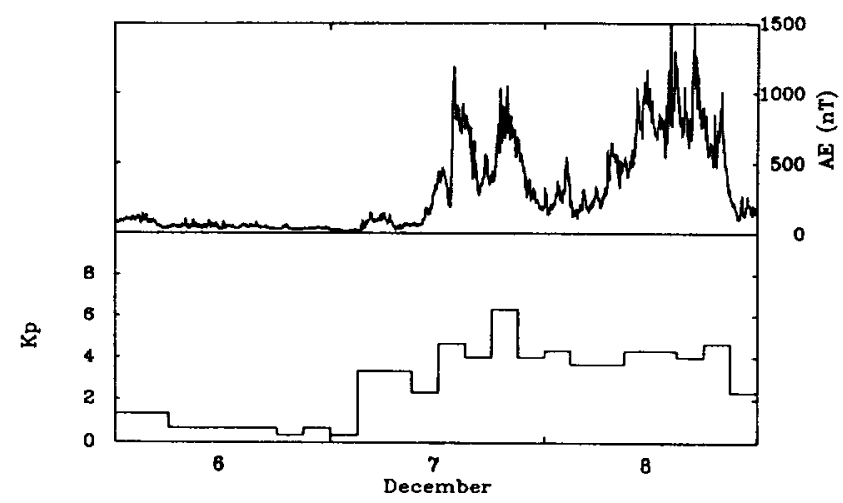

Figure 1. (Top) Auroral electrojet $(A E)$ and (bottom) $K \mathrm{p}$ traces for December 6 to 8, 1982. This plot illustrates the two small geomagnetic storms that occurred on December 7 and December 8. Orbit 7433 occurred at about 1300 UT on December 8.
Deng et al. [1993] showed some comparisons between model results for the December 7 and 8, 1982, geomagnetic storm and data for the same period that were obtained from instruments on board the DE 2 satellite. On the whole the agreement was good at high latitudes, despite the fact that Deng et al. were mainly using derived parameters rather than outputs from the TIGCM in these comparisons. We have confidence that, at high latitudes at least, the model is doing a reasonable job of predicting the effects of geomagnetic storms on the thermosphere/ionosphere system. Therefore we feel that it is a useful exercise to compare the modeled low- to middle-latitude, storm time winds with those measured by the DE 2 satellite during a number of geomagnetic storms to see if there is some general morphology of the changes in these winds that can be associated with the effects of storms. We present these comparisons in the next section.

\section{Changes in the Neutral Winds at Low- to Middle-Latitudes in the Winter Hemisphere During Geomagnetic Storms}

\section{TIGCM Wind Calculations}

Before discussing the changes in neutral circulation that occur during a geomagnetic storm, it is necessary to describe the "normal" quiet time circulation pattern in the low- to middle-latitude winter hemisphere. Figure 2 a gives the NCARTIGCM calculations for this circulation on the $z=2(\sim 350 \mathrm{~km})$ pressure surface. Neutral winds blow from the region of maximum temperatures, which occurs near 1500 hours local solar time, into the region where temperatures are coolest, just before local dawn. The meridional component of these winds dominates during the daylight hours, but the zonal component becomes the more important component after dark. The most poleward winds in the plot of the storm time winds (Figure 2b) occur at $37.5^{\circ} \mathrm{deg}$., so that direct auroral effects are largely eliminated. Although two dimensional zonal mean models [e.g., Roble, 1986] produce a picture in which there is a reversal of the meridional wind in the winter hemisphere so that it is blowing equatorward to very low latitudes during geomagnetic storms, in three dimensions the picture is more complicated. There are very strong local time variations, with the two-dimensional picture being applicable near local dawn but not through much of the day. In the afternoon, the poleward winds decrease in magnitude for the storm modeled here, but they do not reverse direction in the latitudes plotted in Figure 2. The overall impression that this plot of the storm time winds gives is that although the general pattern of the circulation remains much the same as the quiet time pattern (except near dawn), the winds associated with the diurnal tide are weaker.

This weakening of the diurnal tide is made clearer in Figure 3, which shows the difference between the modeled storm time winds and the modeled quiet time winds. There is very little change in the diurnal tide in the afternoon (magnitude differences of $20-25 \mathrm{~m} / \mathrm{s}$ for 1500 local solar time (LST) at $37.5^{\circ} \mathrm{N}$, and $10 \mathrm{~m} / \mathrm{s}$ at $22.5^{\circ} \mathrm{N}$ ), but the small changes that occur tend to be almost exactly opposite in direction to the tidal winds. Much larger changes occur in the period after nightfall (magnitude differences of $\sim 180 \mathrm{~m} / \mathrm{s}$ for $2100 \mathrm{LST}$, at $37.5^{\circ} \mathrm{N}$, and $60 \mathrm{~m} / \mathrm{s}$ at $22.5^{\circ} \mathrm{N}$ ). These changes 
a)

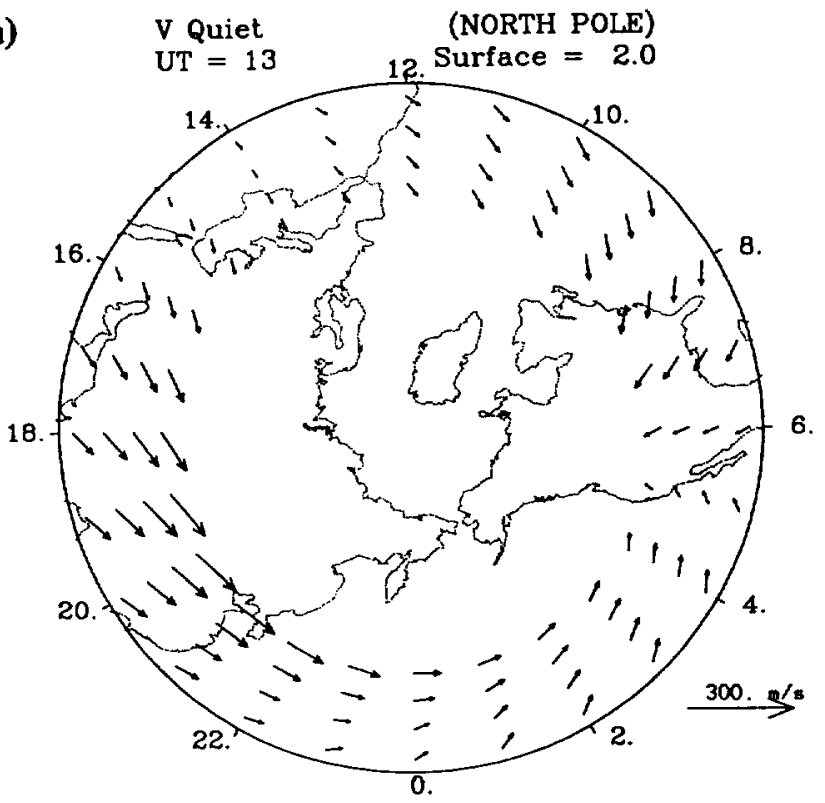

LATITUDE/LOCAL TIME

b)

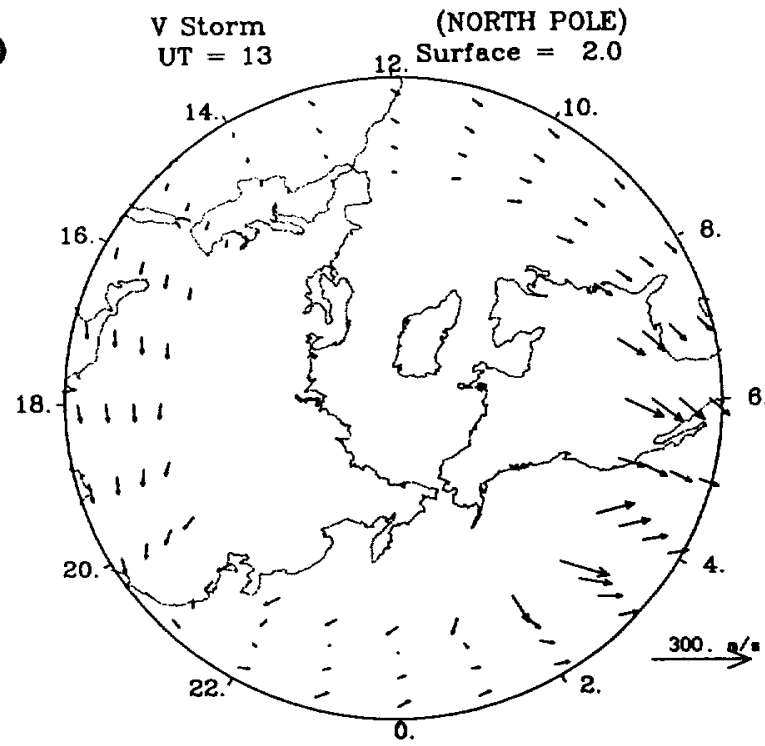

LATITUDE/LOCAL TMME

Figure 2. TIGCM calculations of the circulation associated with the diurnal tide. (a) Quiet-time circulation pattern. (b) Storm-time pattern. In both cases the winds are only plotted for the region between $20^{\circ}$ and $40^{\circ} \mathrm{N}$, so that direct, highlatitude auroral effects are not shown. These winds are calculated for a NCAR-TIGCM simulation of the December 8 storm and the equivalent quiet day. All model results are plotted in geographic coordinates.

tend to be zonal in direction rather than meridional, again opposite to the direction of the quiet time diurnal tide. Large wind changes also happen in the period from midnight to about 8 a.m., and are generally in an equatorward sense (magnitude differences of $\sim 180 \mathrm{~m} / \mathrm{s}$ for $0600 \mathrm{LST}$, at $37.5^{\circ} \mathrm{N}$, and $110 \mathrm{~m} / \mathrm{s}$ at $22.5^{\circ} \mathrm{N}$ ). In the period from about 10 a.m. to midday the changes are again in a direction opposite to the tidal winds. The numerical values given in this paragraph should be treated with caution, because, apart from any uncertainties that might exist with the model representation of the differences, systematic errors may occur owing to variations in the interplanetary magnetic field direction, universal time and storm size.

\section{DE 2 Results}

Similar wind patterns occur in other TIGCM simulations when several hours have elapsed since the commencement of a geomagnetic storm; thus the pattern is fairly universal in model calculations. The question then arises whether we can find supporting evidence for these predictions in observational data. Because of the geometry of the DE 2 orbit, the satellite was restricted to one local time plane for any particular geomagnetic storm. Thus if we study only one storm, we cannot gain much information about the spatial structure of the disturbance. Furthermore, the orientation of the satellite on December 7 and 8 was not the most interesting one in terms of changes that could be seen in daytime winds. The daytime pass occurred at 1760 hours LST, a time in which the changes in neutral winds were expected to be small. Therefore we also looked at other storms during which data existed in the winter or equinoctial hemispheres. There are expected to be some differences between these data and the NCAR-TIGCM output (apart from systematic ones) because the data are presented in geomagnetic coordinates while the model results are presented in geographic coordinates. Thus the comparison between the two is not direct. However, it is likely that other differences such as those that are due to storm size will be even more influential in affecting these comparisons.

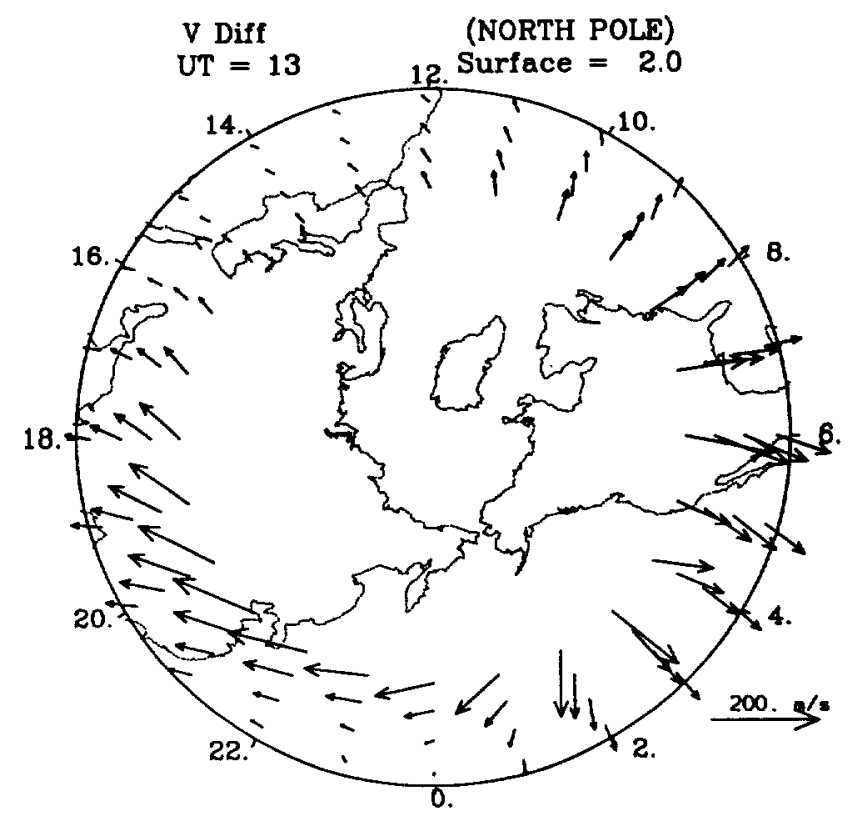

\section{LATITUDE/LOCAL TIME}

Figure 3. TIGCM calculations of the difference between the winds shown in Figure 2. This plot indicates the general decrease in the magnitude of the winds associated with the diurnal tide. 
Figure 4 displays the differenced neutral winds for several orbits, each one corresponding to a different geomagnetic storm. Middle- and low-latitude wind data were available for all of these winter and equinox passes. In all cases, sufficient time has passed since the start of the storm to permit the dissipation of the large wave that is generated by the initial upwelling at the start of the storm [e.g., Mayr et al., 1984; Prölss, 1993; and the references therein]. Also, the orbits have been carefully selected to ensure that the quiet and storm time orbits take place at approximately the same universal time, because the winter temperature structure and, consequently, the pressure-gradient-driven tidal winds also change noticeably with universal time. However, we made no correction for any EUV-driven changes in the neutral wind pattern that may have occurred in the day or two between the quiet time and storm time orbits, because tidal-driven neutral winds (as opposed to neutral temperatures and composition) do not appear to depend strongly on changes in EUV flux (T. L. Killeen et al., unpublished manuscript, 1995). Note that when the difference vectors are dashed, FPI data (meridional wind component) were not available in either the quiet time orbit, the storm time orbit, or both.

The first orbits that we will discuss are $3434 / 3418$. Orbit 3434 occurred more than 6 hours after the commencement of a small geomagnetic storm early on March 22, 1982. At this time the orbit of the DE 2 satellite was oriented along the 10.6 hours local solar time plane. The satellite was flipped, so no FPI data were available, permitting us to study the changes in the zonal component only. A small change in the zonal wind

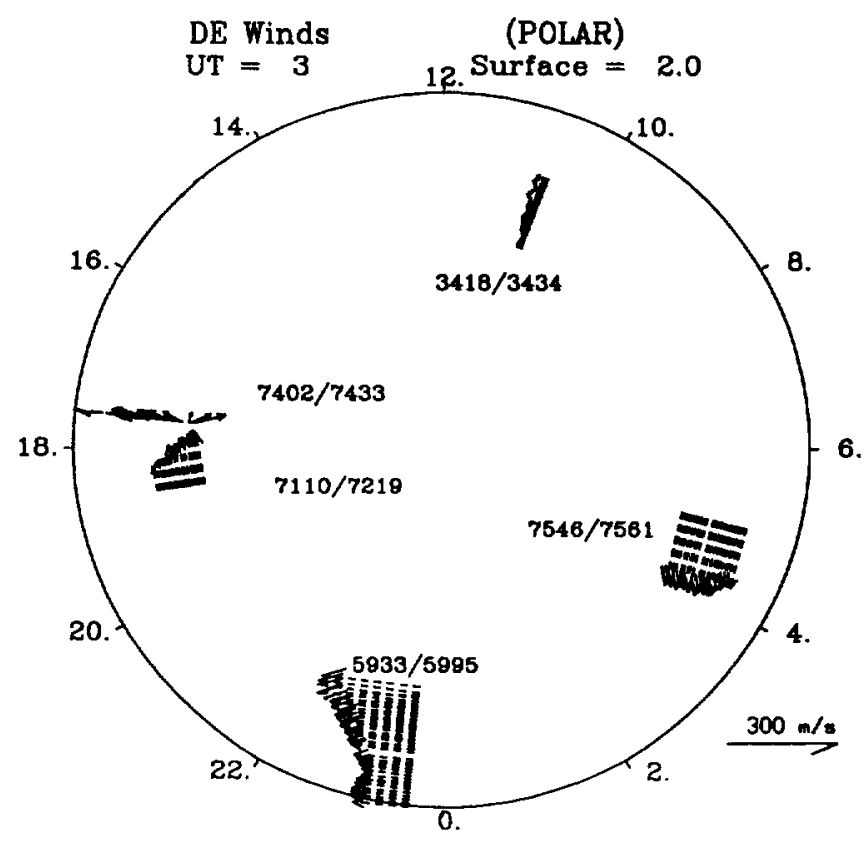

LATITUDE/LOCAL TIME

Figure 4. The equivalent to Figure 3 but now using data from the DE 2 satellite. Data are selected from a number of storms that occurred in the winter and equinox periods. When the vectors are dashed, it means that no FPI (meridional) winds were available. Geomagnetic latitudes are used in all plots of the DE 2 data, but because the satellite was polar orbiting, local solar times are fixed. The times around the dial in this plot refer to local solar times. component of about $30 \mathrm{~m} / \mathrm{s}$ in an eastward direction occurred during the storm time orbit. This change is consistent, in both magnitude and sign, with the changes that the NCAR-TIGCM predicted at this local time for the December 8 geomagnetic storm.

Figure 3 also indicates that only small changes should occur between the storm time and quiet time winds in the late afternoon. Orbits 7433 and 7402 occurred during the December 8,1982 , storm and during the quiet-time preceding the December 7, 1982, storm, respectively. As expected, the changes that are seen between the storm and quiet time winds are small at this time. Note that this orbit pair, and another orbit pair occurring at about the same local time (7546/7561) which behaves similarly, indicate that the two-dimensional, zonal-mean picture of strong equatorward changes in the meridional wind occurring at all local times does not describe the situation that is actually occurring in the thermosphere.

However, as can be seen in Figure 3, quite large changes occur in the storm-time zonal winds soon after dark. Orbit 7219 occurred on November 24, 1982, during a very large geomagnetic storm [e.g., Burns et al., 1992a, b], whereas orbit 7110 occurred after a sustained period with little geomagnetic activity. The antisunward zonal component of the low- to middle-latitude neutral wind decreased greatly during this storm, again in agreement with model calculations. Although no FPI data were available for comparison purposes in orbit 7110 , there is not a large equatorward component to the wind in orbit 7219 , the storm time orbit. This observation is also consistent with the NCAR-TIGCM calculations of the expected storm time circulation in this region, and again is in disagreement with the two-dimensional zonal-mean description of the changes that occur to the neutral winds.

Another large geomagnetic storm occurred on the September 6, 1982. The time of this storm is, of course, that of an equinox storm rather than that of a winter storm. During this storm, the conditions in the southern hemisphere are equivalent to those that occur in the winter hemisphere. This lack of a long equinox period is common in the upper thermosphere [e.g., Carlson and Crowley, 1989]. Again the low- to middle-latitude winds behave much as they do in Figure 3 , if the size of the storm is taken into account. At this time the DE 2 satellite was in its flipped mode in which the FPI could not measure the meridional component of the neutral wind, so only the zonal component is displayed. Orbit 5995 occurred some 12 to 14 hours after the commencement of a second main phase of this storm, while its companion orbit occurred immediately before the commencement of the first main phase. Even for the small storm that was modeled, large changes were expected in the zonal wind at local solar times between 2100 LST and midnight LST. In Figure 2, zonal winds have decreased from quiet time values of about $150 \mathrm{~m} / \mathrm{s}$ to storm time values of about $0-50 \mathrm{~m} / \mathrm{s}$. When we look at a large storm, such as the one that occurred on September 6, these changes near midnight are even more obvious. Zonal winds have reversed, so that instead of blowing eastward toward dawn as they were during orbit 5962, they are now blowing westward toward dusk.

The last set of orbits on Figure 4 indicates some of the changes that can occur just before dawn. Orbit 7561 occurred during a small geomagnetic storm that happened on December 16, 1982. No FPI data existed for the predawn period (such data were available in the afternoon sector, however), so we discuss only the zonal component. This period is the only one of 
those considered in which the patterns of change in the data are not consistent with those in the model. The reasons for this will become more obvious when we discuss the causes of the wind changes later in this section. On December 16, 1982, unlike December $8, B_{y}$ was strongly positive, so that the regions into which the convection pattern advects energy were substantially different between the two storms. These differences in the $Y$ component of the interplanetary magnetic field alter the distribution of pressure gradient and ion drag forces in the postmidnight, low- to middle-latitudes, leading to large differences in the wind pattern in this sector. Thus, although the wind changes in this sector during the December 8 storm were small, there were strong differences in the zonal winds between quiet and storm times on December 16, 1982.

\section{TIGCM Forcing Calculations}

Killeen and Roble [1984] developed a diagnostic processor for the NCAR-TGCM that analyzed the terms that cause changes in the momentum equation. We use this processor here to understand how changes in the high-latitude thermosphere can affect the low- to middle-latitude regions. The changes in these forcing terms between storm and quiet times at 1300 UT during the December 8,1982 storm will be discussed a little later. Before discussing these differences, it is necessary to describe the major forcing terms that maintain the diurnal tidal winds at this altitude (near $350 \mathrm{~km}$, pressure surface $z=2$ ) during geomagnetically quiet times (see Figure 2 for this circulation).
Generally, this quiet time circulation is dominated by the diurnal tide, although there is also a small seasonal component. Heating during the daytime causes maximum temperatures to occur near 1500 hours LST. Downward heat conduction removes heat throughout the day and night, so, because of the absence of solar EUV-driven heating at night, a temperature minimum develops at around 0400 hours or 0500 hours LST. Expansion and compression of the thermosphere alter the picture somewhat, primarily by modifying the amplitude of the diurnal tide (e.g., T. L. Killeen et al., unpublished manuscript, 1995), but the net effect is a fairly strong temperature gradient from the afternoon to the early morning hours. This temperature gradient results in large pressure differences that drive gas from the afternoon toward the early morning (Figure 5c). However, these pressure gradient forces are compensated to a large degree by the drag effects of ion-neutral coupling (Figure 5a). The individual accelerations are greatest during the daylight hours, since pressure gradients are also largest at these times, but the compensatory effects of viscous and ion drag also maximize during daytime. Ion drag is not very important between midnight and dawn, when electron densities are small. The Coriolis force can be locally important, but at these latitudes and altitudes, it is generally not as important as the aforementioned terms on a hemispheric basis.

Having discussed the causes of the quiet time, low- to middle-latitude circulation pattern, we can now consider why this pattern changes during a geomagnetic storm. Figure 6 shows the changes that occur in the major neutral forcing

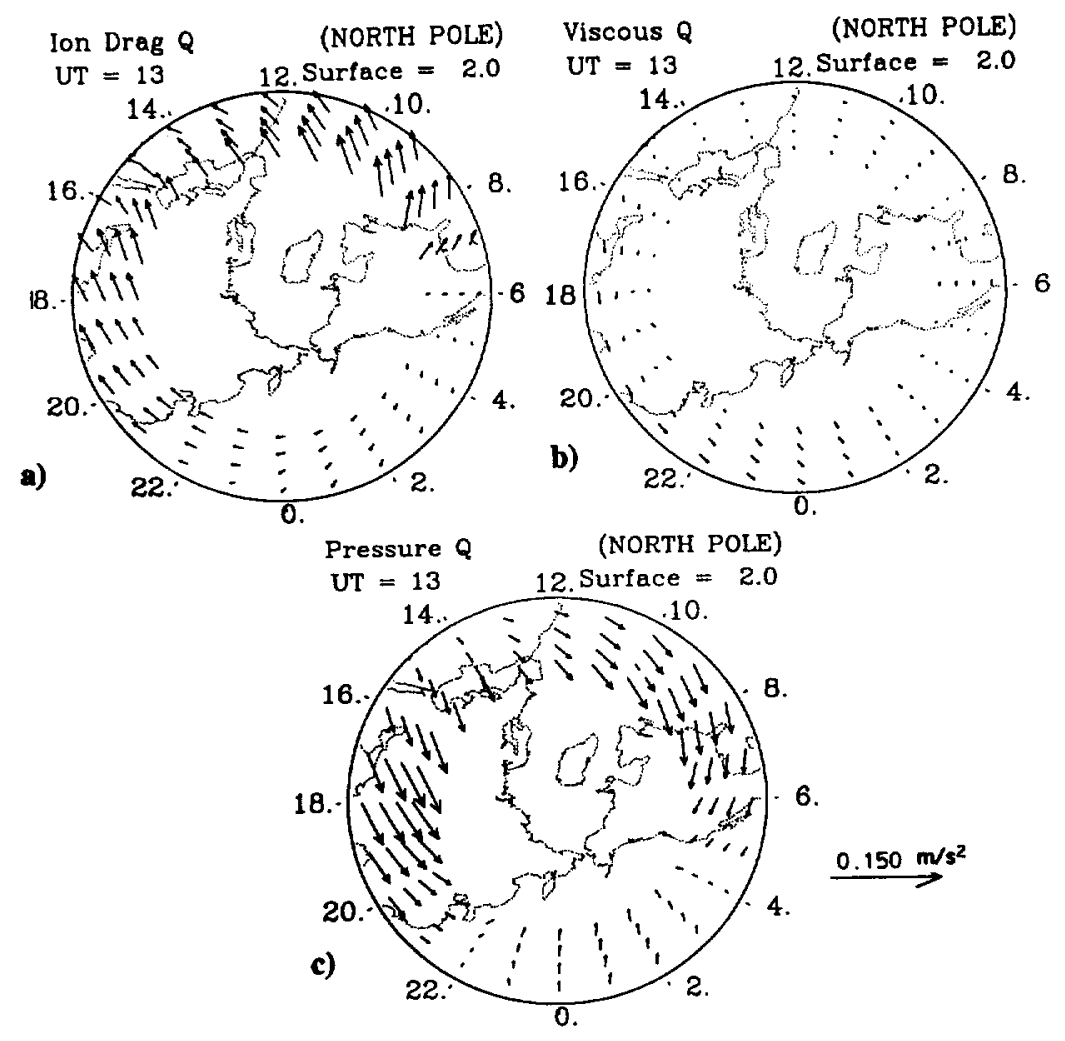

LATITUDE/LOCAL TME

Figure 5. The major terms that force the winds during quiet geomagnetic times (see also Killeen and Roble [1984]), as calculated by the NCAR-TIGCM. The Coriolis force is relatively unimportant at this altitude. The individual plots are (a) ion-neutral coupling, (b) viscous drag, and (c) pressure gradient forces. 


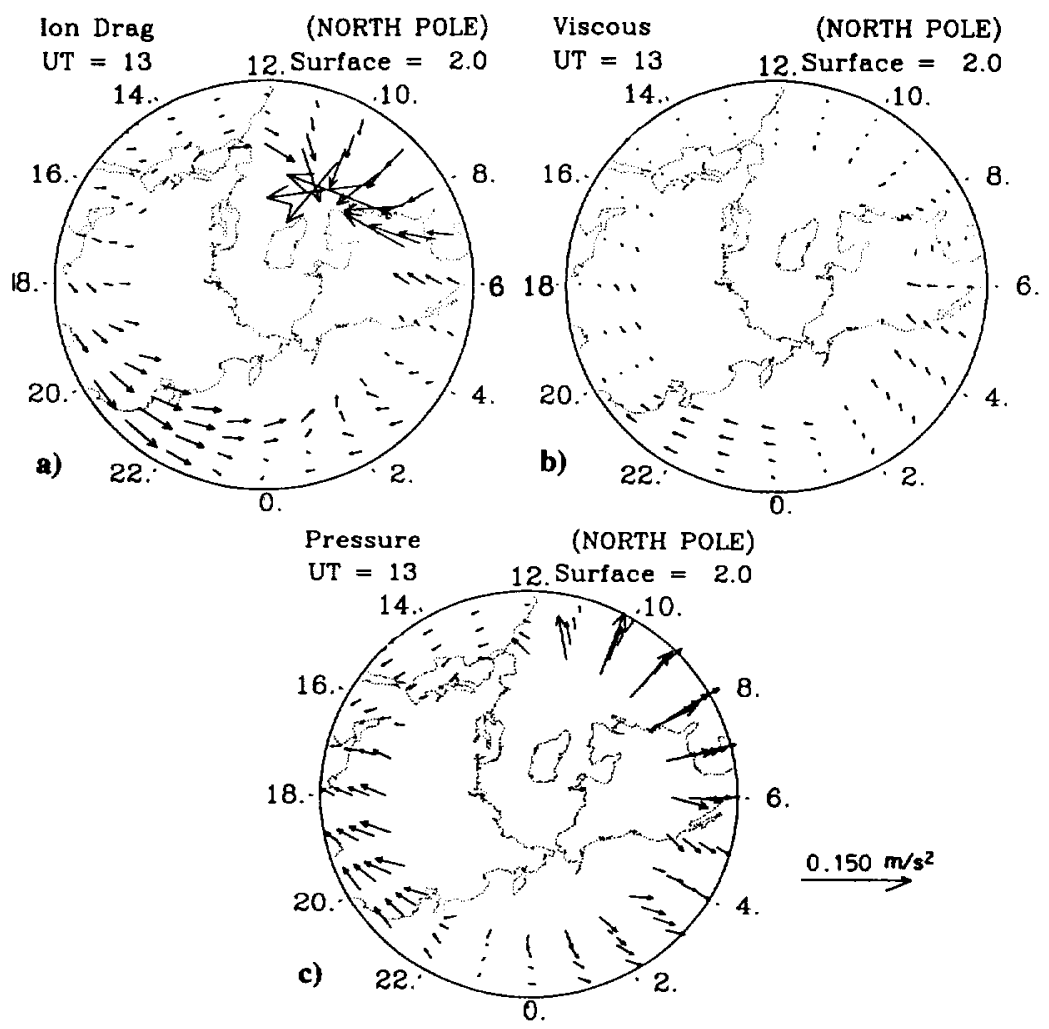

LATITUDE/LOCAL TIME

Figure 6. The changes between storm-time forcing terms and the quiet-time terms shown in Figure 5 . The individual plots are (a) ion-neutral coupling, (b) viscous drag, and (c) pressure gradient forces.

terms between storm time and quiet time. The scale is the same on this plot as it was on the previous one, allowing direct comparisons to be made between the two plots. The dominant changes occur in the pressure gradient forces. During the storm, energy is pushed into the early morning sector. This heats up this region and restricts the normal day-to-night energy flow. In turn, this restriction also causes changes in the low- to middle-latitude, thermal structure (see section 4).

The effect on the acceleration of the neutral gas is also major, as the changing temperature distribution affects the pressure gradient force. Thus there is a large increase in the relative equatorward acceleration due to pressure gradient forces in the region between midnight local time and 0900 hours LST. These changes drive an actual reversal of flow from poleward flow to equatorward flow (the net pressure gradient force is now equatorward) that can be seen in Figure 2. Between dusk and midnight, changes in the pressure gradient force are mainly zonal. Flow in this region is also primarily zonal in geomagnetically quiet times, and these storm time changes in the pressure gradient forces represent a major decrease in the normal day-to-night pressure and temperature gradients. There are no major changes in the pressure gradient forces between 0900 hours LST and 1800 hours LST. This lack of variation means that relatively small changes in neutral wind are seen at these local times (see Figure 3).

Both the viscous and ion drag forces act primarily to compensate for the changes in the pressure gradient forces. In the early morning hours, when electron densities are low on this pressure surface, most of the compensatory effect at these altitudes is a result of enhanced viscous drag. After dawn, as electron densities increase and before the large equatorward pressure gradients dissipate, ion drag is commensurate with viscous drag in restricting the effects of the pressure-gradientdriven, equatorward acceleration. There is a short period from about 1000 hours local solar time until about 1200 hours local time when changes in pressure gradient forces are meridional and changes in viscous drag are minimal, but when ion drag has a small zonal component. This increase in the zonal component of ion drag is probably caused by the increase in electron densities that is associated with positive storm effects. Any such effects are drowned out elsewhere, as stronger dynamic effects, caused by pressure gradient changes, dominate. Changes in the Coriolis force are small in comparison with those that occur in the pressure gradient and ion drag forces.

Changes in the neutral circulation also cause changes in the way energy is redistributed. Not only do these changes in redistribution affect the final morphology of the heating resulting from the energy that originally came from the magnetospheric source at high latitudes, but they can also affect the morphology of the heating in the low-middle latitudes that results from EUV radiation. We consider this second type of change in energy redistribution in the next section and consider its implications for neutral temperatures, composition, and density.

\section{Low- to Middle-Latitude Changes in Neutral Temperatures in the Winter Hemisphere}

In the previous section, we discussed low-middle latitude, neutral circulation changes that were driven by geomagnetic 
storms. These changes in circulation also affect the distribution of energy in the low-middle latitudes. Normally, the diurnal temperature structure that is produced by solar heating and downward heat conduction is altered significantly by upward vertical winds in the afternoon and evening and downward vertical winds between midnight and the late morning hours. These vertical winds are driven by convergence and divergence, so the alterations to the circulation that were discussed in the previous section will lead to changes in the distribution of this heating through changing compression and expansion.

In this section we look at TIGCM predictions of these changes in vertical winds and their effect on changes in the heating and cooling terms for the neutral gas. No reliable vertical wind measurements are available to compare with the model predictions, but later in this section the predicted increases in temperature are discussed with reference to observations.

\section{TIGCM Temperature and Heating Term Calculations}

Figure 7 gives NCAR-TIGCM calculations of the changes in vertical winds between storm and quiet times in the low- to middle-latitude winter hemisphere on a constant pressure surface at 1300 UT. Vertical winds undergo a relative downward change between storm and quiet times of around $1 \mathrm{~m} / \mathrm{s}$ throughout most of this region. During the daytime, vertical neutral winds are normally upward and thus have a cooling effect on the thermosphere, while at night they are mostly downward and they warm the thermosphere (T. L. Killeen et

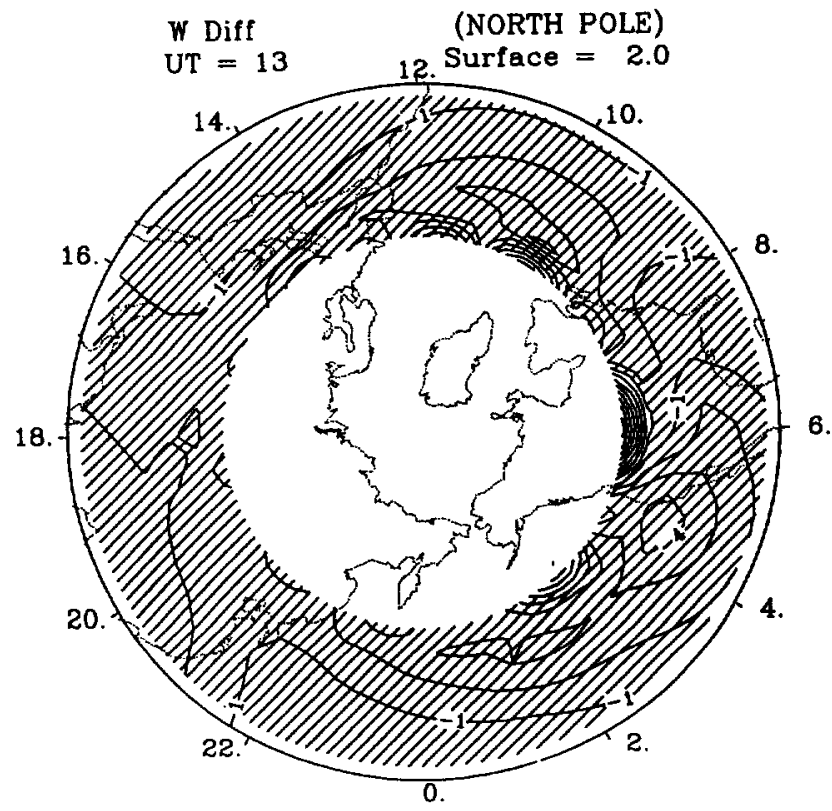

LATITUDE/LOCAL TIME

Figure 7. The changes in vertical winds between storm time and quiet time, as calculated by the NCAR-TIGCM for the December 8, 1982, geomagnetic storm. Units are meters per second. When values are negative, the contours are drawn over by angled lines. So, in this case, where all the contours are negative, all of the contours are drawn over by these lines. al., unpublished manuscript, 1995). They also alter the compositional balance by transporting nitrogen-rich air upward during the day and downward at night [Burns et al., 1989]; these compositional changes will be discussed in more detail later. However, during geomagnetic storms, these upward winds decrease during the daytime, so the rate of expansion should decrease, and hence the cooling rate due to thermal expansion should also decrease. At night these winds are normally downward, and the increased magnitude of these downward winds during storms results in increased compressional heating. Thus the low- to middle-latitude winter thermosphere heats up during a geomagnetic storm.

In Figure 7, we showed that the vertical winds blowing through a constant pressure surface became less upward (and more downward) at low- to middle-latitudes in the winter hemisphere during a geomagnetic storm. We also suggested that these changes in the vertical wind should have a profound effect on heating and cooling rates in the thermosphere. Before illustrating the importance of changes in vertical winds to low-middle latitude heating, we need to consider the low- to middle-latitude temperature changes that occur in winter during geomagnetic storms.

Figure 8 shows the temperature change (expressed as a percentage relative to the quiet time temperature) that is calculated by the TIGCM at one time during the December 8 , 1982, geomagnetic storm. These temperature changes are positive everywhere in the low- to middle-latitude winter hemisphere, with magnitudes ranging from $12 \%$ in the afternoon to greater than $50 \%$ in the early morning regions. Generally, the trend is that the smallest temperature increases, in terms of percentage change, occur in the afternoon, whereas the greatest temperature increases occur in the early morning hours.

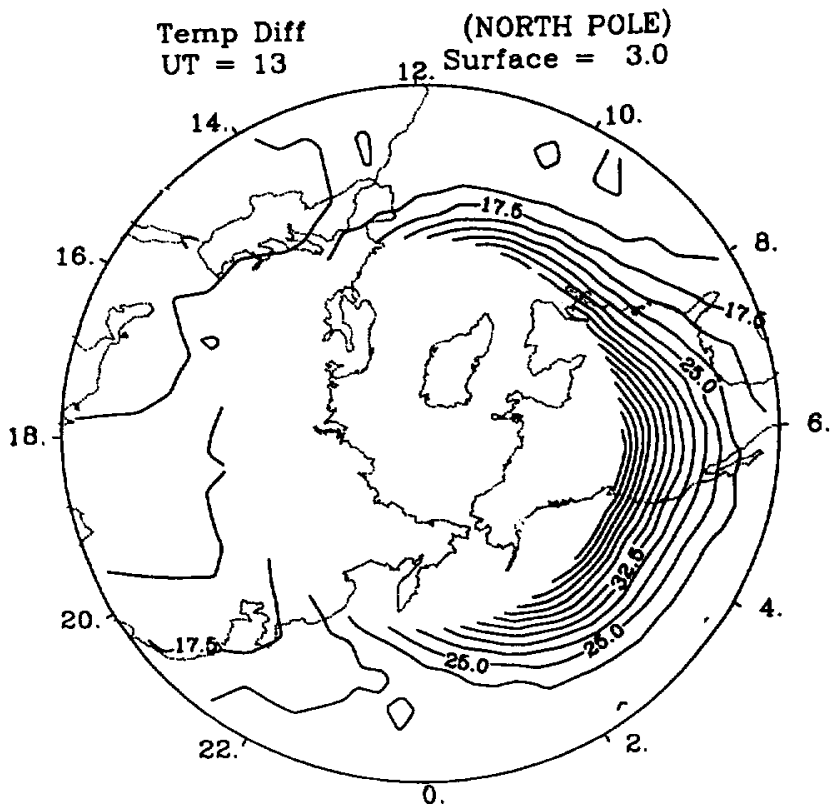

LATITUDE/LOCAL TIME

Figure 8. Low- to middle-latitude temperature changes that were calculated by the NCAR-TIGCM for 1300 UT on December 8, 1982. The plot represents the percentage difference between the storm-time case and the quiet-time case in the low-middle latitudes of the winter hemisphere. 
These temperature changes can be explained in terms of increases in heating and decreases in heat loss between storm and quiet times. Thus heating terms can be divided into those that are responsible for a relative heat gain (temperature increase) and those responsible for a relative heat loss (temperature decrease). Because, as we showed in Figure 8, the low- to middle-latitude upper thermosphere heats up in the winter hemisphere during a geomagnetic storm, the terms responsible for the relative heat gain are of more interest to this study than those responsible for the relative heat loss. Of the terms responsible for the relative heat gain, the compression/expansion term undergoes the most important changes at low-middle latitudes during a geomagnetic storm. Figure 9 gives the importance of this term compared with the sum of all terms that contribute to a relative heat gain. It is clear that this term contributes more than $50 \%$ of the relative heat gain through most of the region between $20^{\circ}$ and $50^{\circ} \mathrm{N}$.

In the two regions where this is not true (a small area during the middle of the afternoon and just after dawn), the relative gain is dominated by changes in downward heat conduction. Overall, most of the increases in heating in this region result from changes in vertical winds blowing through a pressure surface. These changes cause a relative decrease in cooling through expansion and a relative increase in heating through compression.

\section{DE 2 Temperature Changes}

We have shown that NCAR-TIGCM results indicate that low- to middle-latitude temperatures increase during geomagnetic storms, but do observations support these conclusions? To test the TIGCM predictions, geomagnetic storm induced effects in the data must be separated from other potential causal processes. Five such potential causal

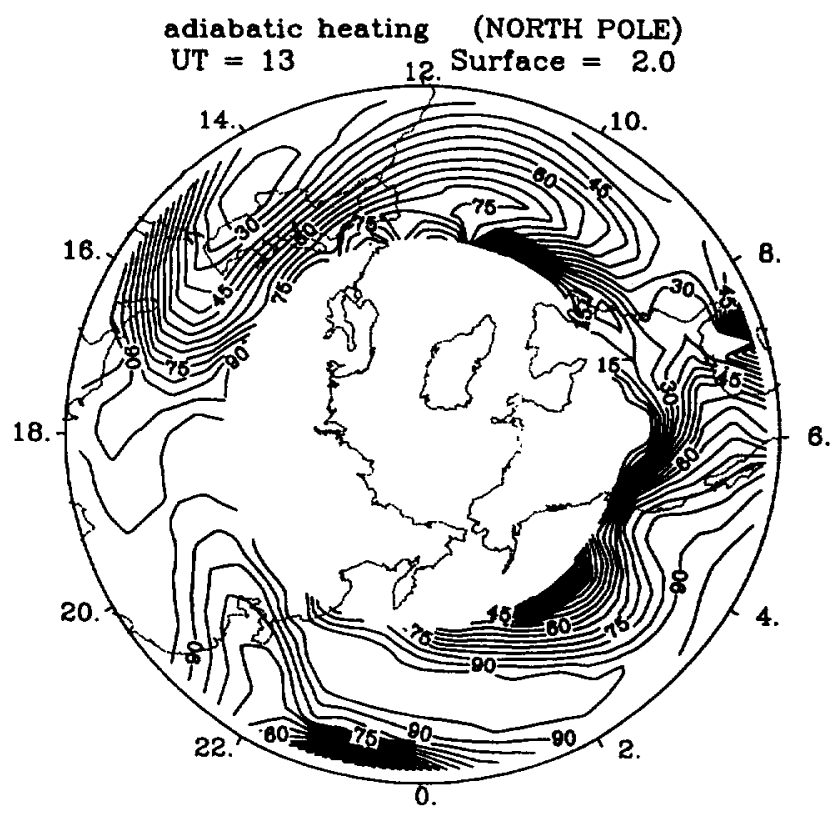

\section{LATITUDE/LOCAL TIME}

Figure 9. TIGCM calculations of the relative importance (percent) of increases in heating through compression (or decreases in cooling through expansion) to the sum of the terms causing extra heating at 1300 UT on December $8,1982$. processes stand out: changes in solar EUV radiation, changes in local time, changes in latitude, changes in the temperature structure due to universal time effects, and changes in position relative to the geomagnetic pole. There is a redundancy in the last two processes: if universal time changes are removed and the local time remains the same, then the effects of changes in position relative to the geomagnetic pole will also be removed.

Two of the causal process (local time effects and latitude changes) are not important when data from the DE 2 satellite are used. This satellite was polar orbiting and maintained itself along roughly the same local time axis for at least a week. Thus when orbits are separated by less than 1 week, changes in temperature that result from changes in local time should be of relatively little consequence. Latitude changes are also not important because the satellite swept through all latitudes during its orbit. Therefore as long as data are available within the region of interest, they can be compared at the same latitude. The other causal processes require more careful treatment before they can be eliminated as a cause for the observed temperature changes.

Two potential sources of error in estimating the effects of geomagnetic storms on the temperature field remain: UT (and, through redundancy arguments, position relative to the geomagnetic pole) changes and EUV changes. Universal time changes between the storm time orbits and their reference quiet time orbits were minimized by searching for suitable quiet time orbits at approximately the same universal time on a different day. This had the effect of reducing the amount of usable data, but provided certainty that our results were not biased by universal time or geomagnetic latitude differences. EUV changes are harder to remove, but MSIS [Hedin et al, 1991, and the references therein] gives a good representation of the changes in temperature that the neutral thermosphere will experience as a result of changing EUV flux. Therefore the quiet time temperature at each point along the satellite track was adjusted by an amount equal to the ratio between the MSIS temperature calculated by using the $F 10.7$ and $F 10.7$ ave appropriate for the storm day (i.e., for the day prior to the storm day) and the MSIS temperature calculated by using the $F 10.7$ and $F 10.7$ ave conditions appropriate for the quiet, comparison day (i.e., for the day prior to the comparison day). In both cases, MSIS was run for quiet geomagnetic conditions. Generally, this adjustment was small, because the quiet time orbits that were chosen occurred within a day or two of the storm time orbits, and $F 10.7$ and $F 10.7$ ave did not change greatly over this short interval. An extra uncertainty is introduced into our calculations by using MSIS to characterize the changes in temperature caused by changing $F 10.7$ fluxes (i.e., our results are dependent on how well MSIS models the F10.7 variation), but because the changes in the temperature that result from this modification are generally small, the uncertainty introduced should also be small.

Figure 10 shows the relative temperature changes between storm and quiet times for orbits passing through three storms (and for three very different local times). In all cases the orbits were selected to correspond to times at least 6 hours after the start of the storm, and in two of the cases (March 2, 1982, and September 6,1982 ) the orbit occurred more than 12 hours after the storm onset. This criterion was used to ensure that we looked at the longer term effects of the geomagnetic storms, rather than at any transient effects that may occur early in a storm (e.g., the passage of the large waves that are generated 


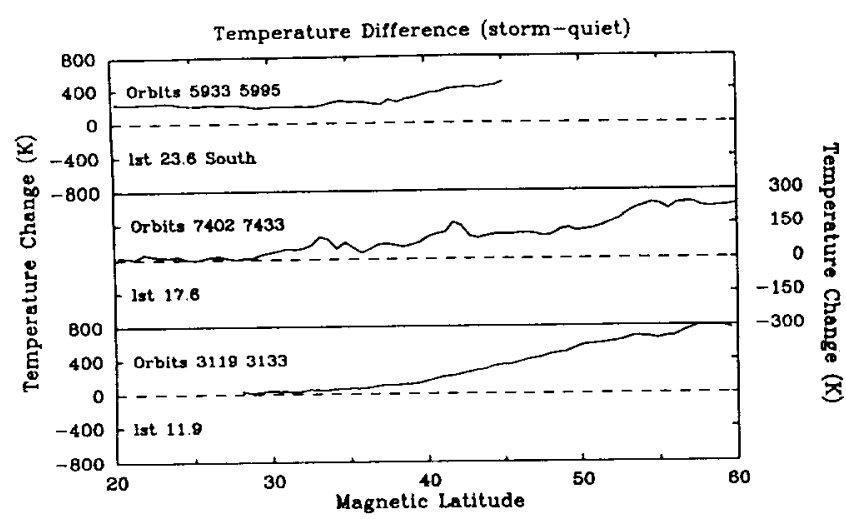

Figure 10. Relative temperature changes (percent) between storm and quiet orbits for three storms that occurred during the DE 2 mission. The three storms occurred on (top) September 6 , 1982, (middle) December 8, 1982, and (bottom) March 2, 1982. The data are compared at the set of heights corresponding to the storm time orbit. The quiet time orbits have been adjusted to account for any height differences and for variations in solar flux in the way described in the text. The words orbits refer to the two orbits used to make the calculations, while the letters Ist followed by a number refer to the local solar time of the observations.

at the onset of storms). The orbits shown in Figure 10 are arranged by decreasing local time from top to bottom.

The top panel is a midnight pass through the large storm that occurred on September 6,1982. Southern hemisphere data are used in this plot because the quiet time data used in the comparison correspond better to data appropriate to the southern hemisphere winter conditions than to the northern hemisphere winter conditions. Although the nature of the transition between summer and winter conditions is not certain, various aspects of the thermal and compositional structure both during the storm and on the preceding quiet days suggest that southern hemisphere winter and northern hemisphere summer conditions prevailed (e.g., higher temperatures and $\mathrm{N}_{2}$ densities in the northern hemisphere). Large temperature increases were seen at all latitudes during this orbit. They were large at high latitudes, but the magnitude of the increase was less in the middle and low-middle latitudes. As the satellite moved to low-middle latitudes, temperature increases reached a minimum of about $200-300 \mathrm{~K}$; a value that is consistent with earlier observations of temperature increase discussed by Chandra and Spencer [1976] and Nisbet et al. [1977].

The second panel is for an orbit that passed through the geomagnetic storm that we have modeled in this paper. This was a relatively small storm, and the magnitude of the associated temperature changes reflects the storm's size. Instead of the $800 \mathrm{~K}$ temperature changes that were seen at $60^{\circ} \mathrm{N}$ in the March 2 storm (see the next paragraph), temperature increases during this storm were a much more modest 200-300 $\mathrm{K}$ at the same geomagnetic latitude. Generally, the pattern of temperature changes for this orbit is similar to that calculated by the NCAR-TIGCM for this local time. The largest temperature changes are seen at the highest latitudes; but at $50 \mathrm{deg}$. geomagnetic latitude their magnitude is of the order of $10 \%$ (about $100 \mathrm{~K}$ ). At lower latitudes, temperature increases are minimal. Two factors may influence this last result. First, the slight increase in $\mathrm{N}_{2}$ density (see
Figure 12) at latitudes between 20 and 30 degrees on a set of constant height surfaces (along the satellite orbit) may indicate that a wave similar to that described by Burns and Killeen [1992a] is still influencing the lowest latitudes. Second, there are indications that the TIGCM calculations overestimate the increases in temperature that occur at low latitudes [Burrage et al., 1992]. Thus, modeled temperature increases are larger than those observed.

The third panel in Figure 10 gives the temperature increases along an orbit that passed along the noon meridian during the major storm that occurred on March 2, 1982. Although this orbit also occurred very close to an equinox, northern hemisphere conditions during quiet times were similar to those occurring during winter. The reason that solstice conditions can prevail at a time so close to the equinox relates to the nature of the transition itself. In the late 1980 s a large campaign was organized to try to characterize the nature of the transition [see Carlson and Crowley, 1989, and other papers in this special issue of the Journal of Geophysical Research]. Instead of gaining information about the transition, the study eventually concentrated on a pair of large storm events that occurred near the equinox. Although this seems to be a negative result as far as knowledge of equinox conditions is concerned, it does point to the fact that the transition is a very rapid event that can be obscured by other geophysical activity, and that solstice like conditions tend to dominate very close to the equinox itself. Thus both this set of orbits and those on September 6, 1982, behave more like solstice orbits than like equinox ones.

In the third panel of Figure 10, very large increases in temperature occur at $60^{\circ} \mathrm{N}$, so scales were chosen that, unfortunately, hide the increases at $30^{\circ} \mathrm{N}$. Overall, temperature increases generally fall off far more rapidly in an equatorward direction along the noon meridian than they do along the midnight meridian. This is a result of the relatively small changes in horizontal wind, and hence changes in divergence/convergence and vertical winds, in the low- to middle-latitude region at this local time.

The temperature changes resulting from two other storms were also studied. These showed similar patterns, but the orientations of their orbits were very similar to two of the orbits discussed above, so they have not been included here. Such temperature changes should also cause changes in some of the other physical variables in the thermosphere. For example, large temperature changes, such as those described in this section, should cause thermal expansion. This, in turn, should result in increases in neutral densities. In the next section, we discuss compositional and density changes that occurred during the same storms as those described above.

\section{Low- to Middle-Latitude Changes in Neutral Composition and Density in the Winter Hemisphere}

A further complication arises when neutral densities from two separate orbits are compared. The satellite's orbit precesses latitudinally, so the heights of the two measurements are not identical. This is not important for temperatures, since the thermosphere is essentially isothermal at altitudes above $300 \mathrm{~km}$. However, neutral densities and composition change exponentially with altitude, so a relatively small change in altitude results in potentially large 
changes in composition and density. In this study, we removed this discrepancy by reducing the individual densities measured during the quiet time orbit to the same altitudes as those that the satellite passed through during the storm time orbit (the data were all measured at altitudes between 300 and $450 \mathrm{~km}$, but the actual altitude varied with position for each individual orbit, and also varied considerably between storms). To do this, we assume that the quiet time thermosphere is in local diffusive equilibrium for the small altitude differences involved. We then adjusted the altitude of the quiet time orbit to that of the storm time orbit. Because the height differences between the two orbits are small in each case, the assumption of diffusive equilibrium should not cause large errors. Similarly, we reduced the quiet time densities, which are expressed in terms of pressure levels, to the same pressure height as the storm time densities by using the same assumptions.

In this section, we present two sets of plots: first, the density and composition changes at a set of constant heights (the set of heights of the satellite orbit that occurred during the geomagnetic storm), and then these parameters at a set of constant pressures (the pressures of the satellite orbit that occurred during the storm). The first thing that we do is confirm the observations by Mayr et al. [1978], Hedin et al. [1977], Prölss et al. [1988] and others that at low latitudes, the densities of all species increase during geomagnetic storms at satellite heights. Next, we check the observations of Prölss [1987], who found that the $\mathrm{O} / \mathrm{N}_{2}$ ratio generally increases by small amounts in the low- to middle-latitude winter hemisphere along a satellite orbit, but occasionally decreases. Last, we examine the data to see whether a consistent pattern in the $\mathrm{O} / \mathrm{N}_{2}$ ratio changes can be found by using a set of constant pressures rather than a set of constant heights.

\section{Changes on Constant Height Surfaces: DE 2 Data}

The first such plot, Figure 11, shows the changes in $O$ density at the height of the satellite as a result of the geomagnetic storm. $O$ densities can increase by over $100 \%$ near $30^{\circ}$ at midnight during a major storm (top panel). Increases in $\mathrm{O}$ density were modest during the small storm that occurred on December 8, 1982 (middle panel). In this case, the satellite orbit was along the dusk meridian, and although $\mathrm{O}$

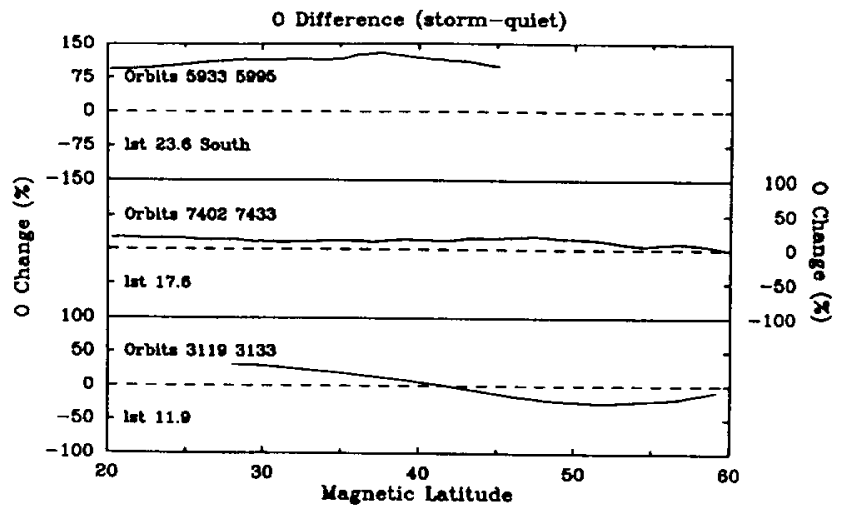

Figure 11. Relative changes (percent) in $O$ density between storm and quiet times at the height of the satellite for three storms during the DE 2 period. The three storms plotted are the same as those plotted in Figure 10.

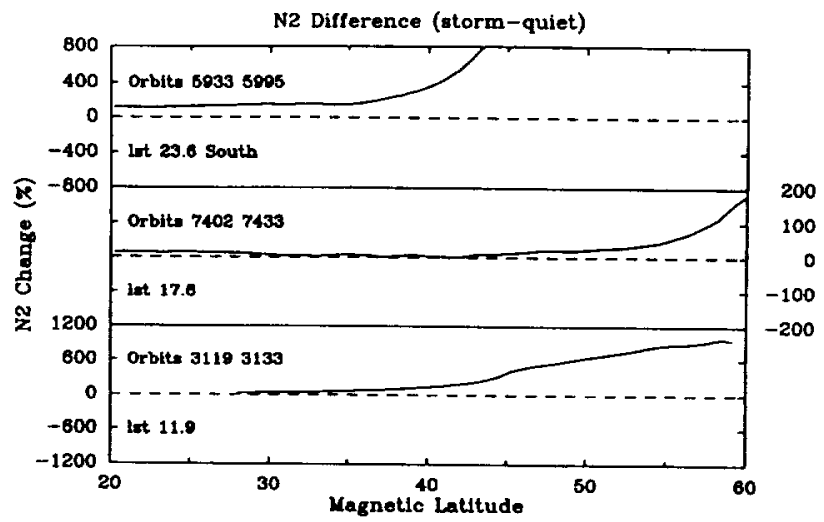

Figure 12. Relative changes (percent) in $\mathrm{N}_{2}$ density between storm and quiet times at the height of the satellite for three storms during the DE 2 period. The three storms plotted are the same as those plotted in Figure 10.

density increases were seen at all latitudes displayed in this plot, the enhancements were of the order of only 10-20\%. The situation was more complicated during the major storm of March 2, 1982. At the higher latitudes in this plot, $O$ densities decreased, an observation that is consistent with previous studies of the response of $\mathrm{O}$ at high latitudes [e.g., Prölss, 1980]. At lower latitudes, $O$ densities are again enhanced, with increases of the order of $30 \%$ or $40 \%$ occurring at $30^{\circ} \mathrm{N}$ (geomagnetic).

$\mathbf{N}_{2}$ densities are also enhanced at the height of the satellite during geomagnetic storms (Figure 12). During the September 6,1982 , storm, $\mathrm{N}_{2}$ densities increased by $100 \%$ or more at geomagnetic latitudes between $20^{\circ}$ and $40^{\circ}$. At higher latitudes, much larger enhancements occurred: at $43^{\circ}$ the increase was $800 \%$. Much smaller enhancements were seen along the dusk meridian during the weak storm that occurred on December 8, 1982. Apart from the highest geomagnetic latitudes shown, where enhancements were of the order of $200 \%$, most enhancements were not much greater than $0-10 \%$. Note that there was a small secondary enhancement of $\mathrm{N}_{2}$ density of the order of about $15 \%$ at latitudes between $20^{\circ}$ and $30^{\circ}$. Although this enhancement may not be statistically significant, it may also be the last stage of a wave propagating through the equatorial region as described by Burns and Killeen [1992a]. No temperature increase was seen in this region, an observation that may be consistent with wave-induced upwelling. The final panel is a little misleading because of the large $\mathrm{N}_{2}$ density increases that occurred at $60^{\circ}$. These were of the order of 1000-1100\% (10 to 11 times), so scales had to be chosen that would accommodate these large increases. However, even at the lowest latitudes for which data were available, $\mathrm{N}_{2}$ densities increased by $30 \%$ during this orbit.

The pattern of $\mathrm{O} / \mathrm{N}_{2}$ changes along the satellite track is much more complex (Figure 13). In practice it is probably better to say that there is no pattern equatorward of the region of large $(>50 \%)$ reductions. During the September 6,1982 , storm the $\mathrm{O} / \mathrm{N}_{2}$ ratio was reduced even at the lowest latitudes plotted. This reduction was of the order of $15-20 \%$ from $20^{\circ}$ to $40^{\circ}$ and was of a much larger magnitude at higher latitudes. Small increases in $\mathrm{O} / \mathrm{N}_{2}$ ratio are seen at low-middle and middle latitudes during the December 8, 1982, storm, but these were $10 \%$ at most. Again, large reductions were seen at the highest 


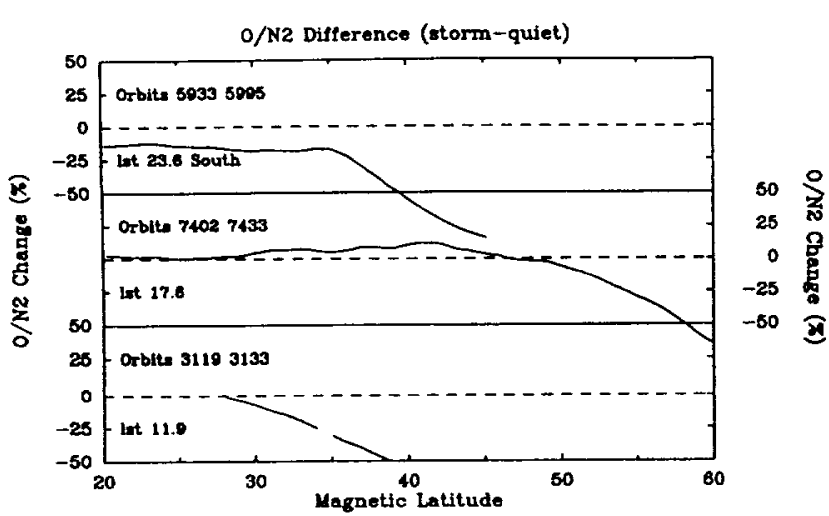

Figure 13. Relative changes (percent) in the $\mathrm{O} / \mathrm{N}_{2}$ ratio between storm and quiet times at the height of the satellite for three storms during the DE 2 period. The three storms plotted are the same as those plotted in Figure 10.

latitudes. No increases were seen during the March 2 storm, but changes approached zero at the lowest latitudes plotted $\left(27^{\circ}\right.$ or $28^{\circ}$ ). On the whole, no consistent conclusions can be drawn about $\mathrm{O} / \mathrm{N}_{2}$ changes at low- to middle-latitudes on a set of constant height surfaces, but small decreases generally dominate. This result is similar to (but mirrors) the conclusions Prölss (1987) drew from $\mathrm{N}_{2} / \mathrm{O}$ ratios.

Generally, our results in this section confirm previous observations that the densities of the major species increase at low and low-middle latitudes during geomagnetic storms [e.g., Mayr et al., 1978; Hedin et al., 1977; Prölss et al., 1988, and the references therein). Apart from the density increases at the lowest latitudes during the December 8, 1982, geomagnetic storm, increases in density were associated with regions in which the temperature increases. However, because the correlation between temperature and density changes is poor, other factors apart from thermal expansion, such as the vertical winds blowing through constant pressure surfaces, must also affect these neutral densities.

\section{Changes on Constant Pressure Surfaces: DE 2 Data}

Variability in density due to thermal expansion can be removed by looking at the density and composition data at constant pressures rather than at constant altitudes. In many ways, looking at constant pressures is more physically meaningful. For example, electron densities ought to be better ordered in pressure coordinates (see section 7).

Figure 14 gives the differences between storm and quiet time $O$ density; in this case the quiet time $O$ densities have been adjusted so that pressures along the path of the quiet time orbit equal the pressures along the path of the storm time orbit. In the top panel there is no area in which $O$ densities increase, but the magnitude of the depletions decreases to about $10-15 \%$ in the region equatorward of about $35^{\circ}$ geomagnetic latitude. Decreases in the $O$ densities become negligible equatorward of about $40^{\circ}$ geomagnetic in the middle panel, and some small increases may occur. There is only a small area equatorward of about of about $30^{\circ}$ geomagnetic in which the magnitude of the $O$ density decrease is small in the third panel. At the highest latitudes plotted here, quite large decreases in $\mathrm{O}$ density are seen in all 3 panels.

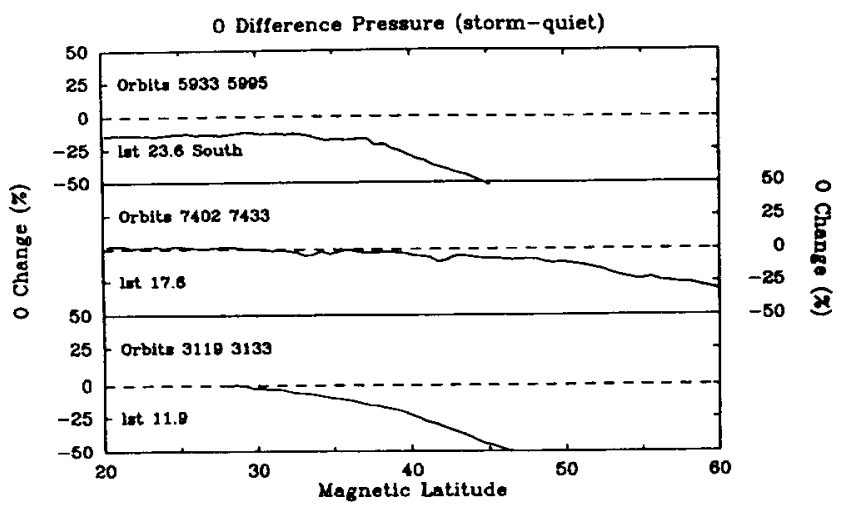

Figure 14. Relative changes (percent) in $O$ density between storm and quiet times at the pressure of the satellite for three storms during the DE 2 period. The quiet time $\mathrm{O}$ density at a point is adjusted to the same pressure level as the equivalent storm time point. The three storms plotted are the same as those plotted in Figure 10.

$\mathrm{N}_{2}$ density changes display a coherent pattern at a set of constant pressures (Figure 15). At low-middle latitudes $\mathrm{N}_{2}$ densities are depleted on a set of constant pressure surfaces during geomagnetic storms. During the midnight pass through the large storm that occurred on September 6, 1982, the magnitudes of these depletions were as great as $30 \%$, but during the smaller storm that occurred on December 8, 1982, the depletions were only $10-12 \%$. Depletions were again of the order of $20-30 \%$ at the lowest latitudes plotted during the March 2, 1982, storm, but this result is hidden by the scale that was chosen to portray the large increases at higher latitudes. In all three cases there was a region poleward of these depletions where $\mathrm{N}_{2}$ densities increased: increases were about $100 \%$ at $45^{\circ}$ during the September 6 storm, about $100 \%$ at $60^{\circ}$ during the December 8 storm, and about $500 \%$ at $60^{\circ}$ during the March 2 storm.

These changes in $\mathrm{O}$ and $\mathrm{N}_{2}$ density have a profound effect on the $\mathrm{O} / \mathrm{N}_{2}$ ratio. At low- to middle-latitudes, increases were seen in the $\mathrm{O} / \mathrm{N}_{2}$ ratio at constant pressures during all three storms (Figure 16). These increases were as high as $50 \%$ during the September 6, 1982 storm (top panel), and of the

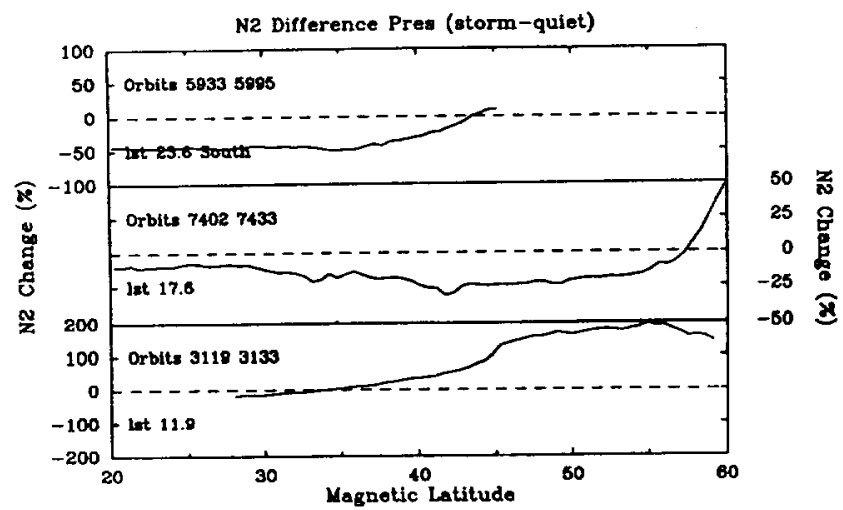

Figure 15. Relative changes (percent) in $\mathrm{N}_{2}$ density between storm and quiet times at the pressure of the satellite for three storms during the DE 2 period. The quiet time $\mathrm{N}_{2}$ density at a point is adjusted to the same pressure level as the equivalent storm time point. The three storms plotted are the same as those plotted in Figure 10. 


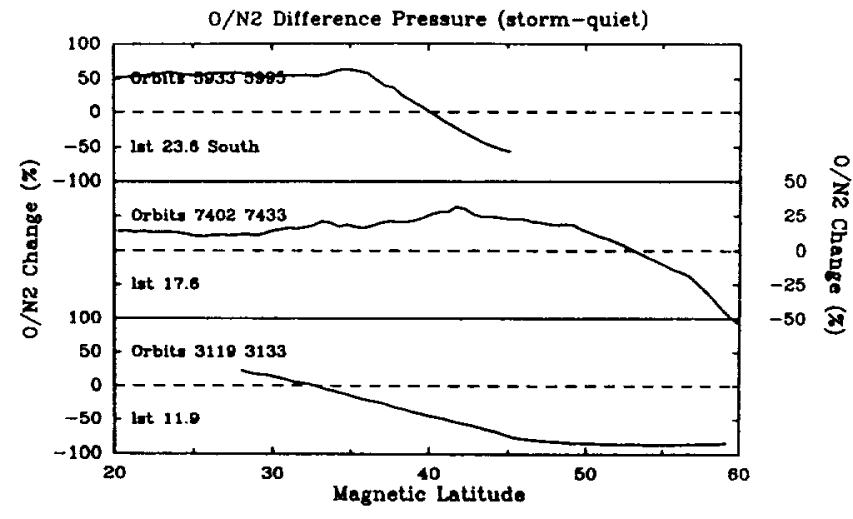

Figure 16. Relative changes (percent) in $\mathrm{O} / \mathrm{N}_{2}$ ratio between storm and quiet times at the pressure of the satellite for three storms during the DE 2 period. The quiet time $\mathrm{O} / \mathrm{N}_{2}$ ratio at a point is adjusted to the same pressure level as the equivalent storm time point. The three storms plotted are the same as those plotted in Figure 10.

order of $15-20 \%$ during the satellite pass through the small storm that occurred on December 8, 1982. Increases in the $\mathrm{O} / \mathrm{N}_{2}$ ratio of $25 \%$ were also seen during the March 2, 1982, storm, but few data were available in the region in which the $\mathrm{O} / \mathrm{N}_{2}$ ratios increase. Only the poleward edge of this region is shown in the bottom panel.

At higher latitudes, the $\mathrm{O} / \mathrm{N}_{2}$ ratio is reduced during geomagnetic storms. Depletions are large at the higher latitudes shown here. During the large storms the $\mathrm{O} / \mathrm{N}_{2}$ ratio was depleted by $75 \%$ and more, and depletions as large as $60 \%$ were seen in the smaller storm (middle panel). The boundary for the transition between the two regimes varies in the three plots. In the middle panel, which is for a small storm in the winter hemisphere, the boundary is relatively close to the pole. For the two large storms (the top and middle panels), both of which occurred near an equinox, the boundary is more equatorward. Given the limited number of storms analyzed here, it is impossible to separate seasonal effects from effects due to the size of the storm and from those caused by changing local times. Thus from the data presented here, it cannot be determined which of these factors is of primary importance in locating this boundary between increases and decreases of the $\mathrm{O} / \mathrm{N}_{2}$ ratio.

In this section, we have looked at the response of neutral composition and density at low-middle and middle latitudes to geomagnetic storms during the winter and equinoxes. Our results have confirmed earlier studies [Mayr et al., 1978; Hedin et al., 1977; Prölss et al., 1988, and the references therein] which show that the densities of all species increase at satellite altitudes during geomagnetic storms in this low- and middle-latitude region. We have also found no strong pattern when $\mathrm{O} / \mathrm{N}_{2}$ ratios are compared along these satellite orbits, although they show similar behavior to the results of Prölss [1987] (who made calculations for $\mathrm{N}_{2} / \mathrm{O}$ ratios) in that the differences were small and tended to be negative (positive for $\mathrm{N}_{2} / \mathrm{O}$ ratios). However, the situation changes markedly when a set of constant pressures are considered. Vertical winds control composition at these latitudes during geomagnetically quiet times [Burns et al., 1989], but these vertical winds change greatly in relation to constant pressure surfaces during geomagnetic storms (see section 4). There is a decrease in the magnitude of upward vertical winds (and an increase in the magnitude of downward winds) blowing through constant pressures at low-middle latitudes. Less nitrogen-rich air is now transported upward (or more nitrogen-poor air is transported downward), and $\mathrm{N}_{2}$ densities decrease. $\mathrm{O}$ densities do not decrease because the vertical gradient of $O$ is relatively small and the effects of decreased expansion (or increased compression) counter the effects of the changed vertical transport. Note that decreased (or increased) vertical winds through a constant pressure surface do not necessarily imply decreased (or increased) vertical winds through a constant height surface. The rate of thermal expansion resulting from the large temperature increases seen at these latitudes may sometimes balance the effects of the reduced divergence of the horizontal winds. The effects of thermal expansion are probably the cause of the differing responses of the $\mathrm{O} / \mathrm{N}_{2}$ ratio along the satellite track at low-middle latitudes that are shown in Figure 13. We address the association between these changes in the $\mathrm{O} / \mathrm{N}_{2}$ ratio and changes in electron density in the next section using results from the NCAR-TIGCM.

\section{Correlation Between Changing Neutral Densities and Electron Densities}

In this section, we present a preliminary theoretical study of the relationship between changes in neutral composition at low-middle latitudes and changes in electron densities in the same region. Figure 17 portrays NCAR-TIGCM predictions of changes in $\mathrm{O} / \mathrm{N}_{2}$ ratio between storm and quiet times on the $z=$ $3(\sim 400 \mathrm{~km})$ constant pressure surface. The model overpredicts enhancements in $\mathrm{O} / \mathrm{N}_{2}$ at lower latitudes (compared with data

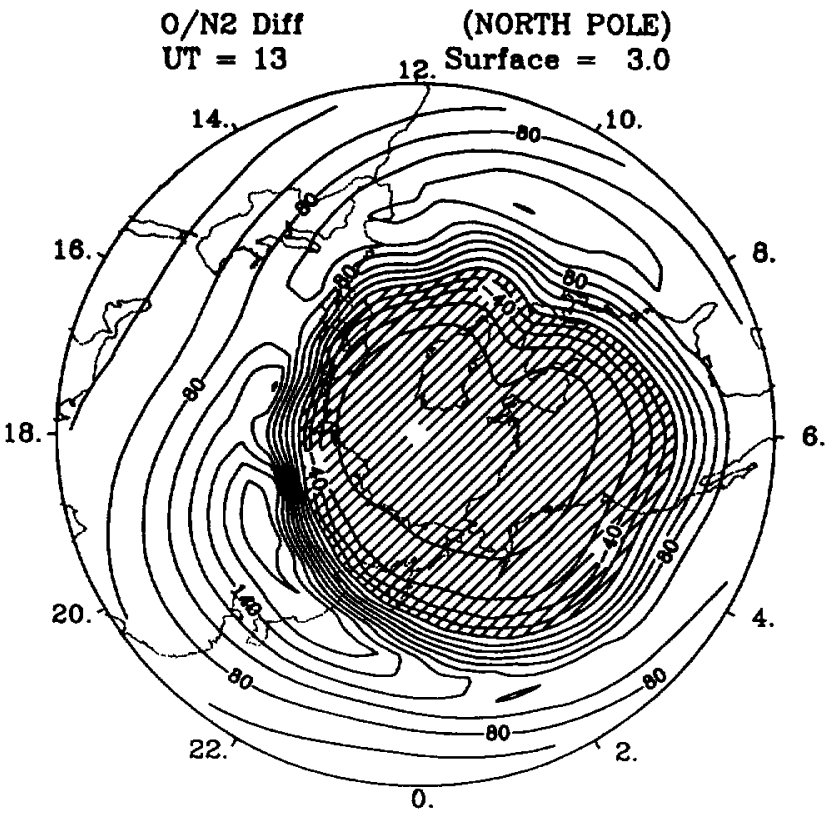

\section{LATITUDE/LOCAL TME}

Figure 17. NCAR-TIGCM predictions of changes in the $\mathrm{O} / \mathrm{N}_{2}$ ratio (percent) between storm and quiet times on a constant pressure surface for the winter hemisphere on December 8, 1982. Negative values are indicated by angled lines drawn over the contours. 
from a satellite orbit that passed through this storm at about the same time) for reasons that we do not yet understand. However, the boundary between depletions and enhancements in the $\mathrm{O} / \mathrm{N}_{2}$ ratio is located in about the same place as the transition that occurred in the center panel of Figure 16, and the sharp gradients in the relative values of $\mathrm{O} / \mathrm{N}_{2}$, which occur poleward of this boundary, are also well reproduced.

Figure 18 shows changes in $N_{m} F_{2}$ (the maximum electron density at the $F_{2}$ peak) in the winter hemisphere that were calculated by comparing storm time TIGCM calculations with quiet time ones. Electron densities are enhanced over the polar cap and around the auroral oval because of the precipitation of energetic electrons that ionize the neutral gas. At slightly lower latitudes there are depletions in electron density, these are the negative storm effects that were discussed in the introduction. They have long been attributed to changes in neutral composition [Seaton, 1956; Duncan, 1969]. The outer boundary of these depletions corresponds fairly well with the outer boundary of the depletions in the $\mathrm{O} / \mathrm{N}_{2}$ ratio shown in Figure 17. Equatorward of these depletions there is a region where the modeled enhancements in $N_{m} F_{2}$ are large. There is a strip of very large enhancements near $40^{\circ} \mathrm{N}$, and smaller but significant enhancements occur at lower latitudes. When Figure 18 is compared with Figure 17, a very strong correlation between the enhancements in the $\mathrm{O} / \mathrm{N}_{2}$ ratio on a constant pressure surface and enhancements in $N_{m} F_{2}$ can be seen in the daylight hours. A time delay does occur between the two with increases (and decreases) in the $\mathrm{O} / \mathrm{N}_{2}$ ratio preceding increases (and decreases) in $N_{m} F_{2}$ by about half an hour to an hour.

As we will discuss in the next section, there are reasons to expect that the large increases in electron density in the premidnight sector should be dependent on the integrated

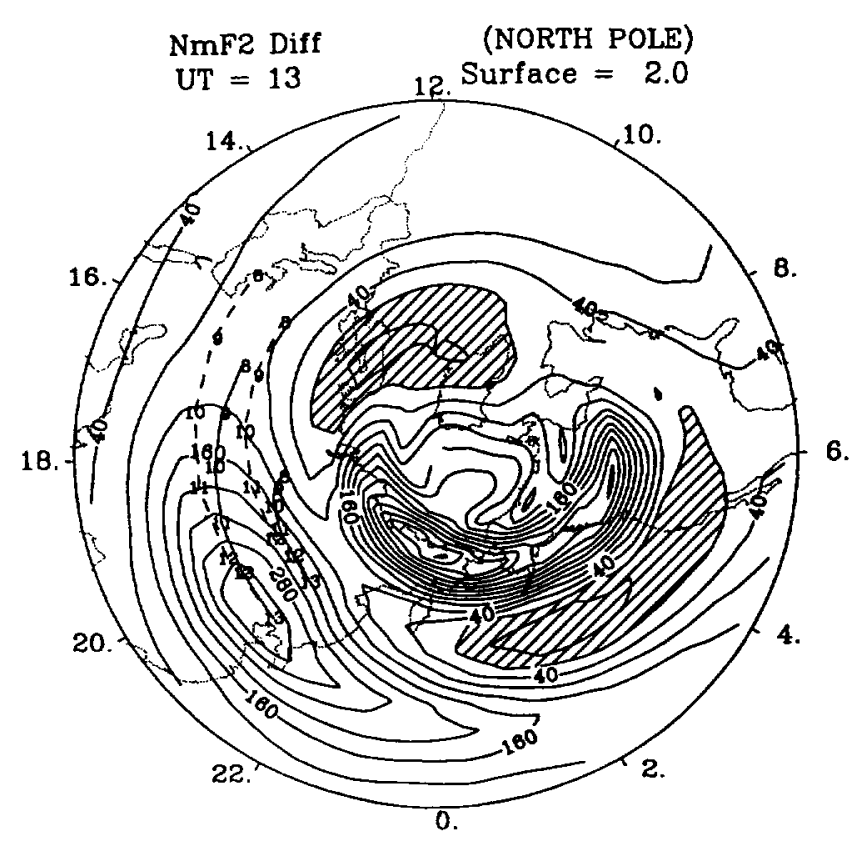

\section{LATITUDE/LOCAL TIME}

Figure 18. NCAR-TIGCM predictions of changes in the value of $N_{m} F_{2}$ (percent) between storm and quiet times for the winter hemisphere on December 8,1982 . Negative values are indicated by angled lines drawn over the contours. decrease of the $\mathrm{N}_{2}$ density due to the storm time effects. Thus if all else was equal, the latitude of the greatest electron density increases should coincide with the latitude of the greatest increases in the $\mathrm{O} / \mathrm{N}_{2}$ ratio on a constant pressure surface. In fact, the largest electron density increases occur at latitudes some $5-10^{\circ}$ lower than the maximum increases in the $\mathrm{O} / \mathrm{N}_{2}$ ratio.

The reasons for this disparity can be determined by studying the terms in the ion continuity equation. If we ignore transport effects, ion density changes at night are dependent not only on the $\mathrm{N}_{2}$ density changes, but also on the residence time of the flux tube in regions where there is no sunlight. If this residence time increases, the effect of the decreasing $\mathrm{N}_{2}$ densities (which lead to the large increases in the $\mathrm{O} / \mathrm{N}_{2}$ ratio) will be ameliorated. We can study this problem of changing residence times by using ion flux tubes. Four of these flux tube trajectories (calculated by using the techniques described by Killeen and Roble [1985, 1986], Cannata et al. [1988], and Burns et al. [1991]) are plotted on Figure 18. The dashed lines represent the normal quiet time trajectories, while the solid lines indicate the storm time trajectories. In all cases the parcels of ionization were traced backward for 5 hours from their locations at 1300 UT ( 2100 LST in all cases, and $55^{\circ}$ and $45^{\circ}$ latitude). During quiet geomagnetic times the parcels of ionization traveled within corotating flux tubes. The situation was different during the geomagnetic storm. The magnetospheric driven ion convection pattern expanded, pushing sunward ion winds into the region of interest. Thus the poleward parcel experienced very strong sunward ion winds during the storm, while the more equatorward parcel experienced much weaker sunward ion winds. The net result of this was that the poleward parcel of ionization was trapped on the nightside for much longer than usual. Thus recombination occurred over a much longer period, and despite the large decrease in $\mathrm{N}_{2}$ density (and hence recombination rates at any particular location), only relatively small increases in electron density were seen. At lower latitudes the magnitudes of the sunward ion winds decrease, and the residence time of the ion parcel in the region after nightfall is only slightly longer than that of a corotating parcel. Hence the changes in the reciprocal of the $\mathrm{N}_{2}$ density become relatively more important at lower latitudes, and increases in $N_{m} F_{2}$ maximize equatorward of the largest decreases in $\mathrm{N}_{2}$ density.

\section{Discussion}

Large changes occur in the thermal and compositional structure of the low and low-middle latitudes during geomagnetic storms [e.g., Burns and Killeen, 1992a; Burrage et al., 1992]. In this current paper, we have shown that these changes are driven by changes in the circulation pattern.

The overall pattern of the changes presented in this paper present a coherent explanation of many of the low- to middlelatitude effects of geomagnetic storms in the winter hemisphere that have been observed over the years. As we discussed in the introduction, increases have been observed to occur in the density of all neutral species at low and lowmiddle latitudes during geomagnetic storms [e.g., Mayr et al., 1978; Hedin et al., 1977; Prölss et al., 1988 and the references therein]. Coupled with these temperature changes there is little change in the $\mathrm{N}_{2} / \mathrm{O}$ ratio at the satellite altitude [e.g., Prölss, 1987], but low- and low- to middle-latitude temperature 
enhancements from 50 to $200 \mathrm{~K}$ have been observed [Taeusch et al., 1971; Blamont and Luton, 1972; Chandra and Spencer, 1976; Nisbet et al., 1977].

The mechanisms described in this paper can explain all of these observations, given the initial change in the pressure gradient force. Given briefly, the progression of these mechanisms is as follows: the winter high-latitude nighttime thermosphere (in particular) is heated by Joule heating; the structure of the horizontal thermal gradients undergoes a change which in turn affects the pressure gradients, weakening the day-to-night and summer-to-winter pressure gradient forces; thus divergence is weakened and convergence is strengthened, causing enhancements in the relative strength of the downward wind. One effect of this is to increase compressional heating, causing higher temperatures in the low- to middle-latitude, winter hemisphere and, consequently, elevated neutral densities on constant height surfaces. If all other things were equal this thermal expansion of the atmosphere would cause elevated $\mathrm{N}_{2} / \mathrm{O}$ ratios on a constant height surface. However, the relative increase in the downward winds acts in the opposite sense on the $\mathrm{N}_{2} / \mathrm{O}$ ratios, causing the apparently inconsistent changes in the low- to middlelatitude regions. The result of these complications is that there are no coherent patterns of change in the winter values of the $\mathrm{O} / \mathrm{N}_{2}$ ratio at low- to middle-latitudes on constant height surfaces. At some local times it will decrease during some storms, but it will increase during others. Similarly, during the same storm the $\mathrm{O} / \mathrm{N}_{2}$ ratio on a constant height surface may increase at some local times at low- to middle-latitudes, but decrease at other local times.

This picture of the circulation changes that occur in the winter hemisphere is an important modification of the twodimensional, zonal-mean view of storm-induced circulation changes [e.g., Roble, 1986]. Instead of a situation in which there is a reversal of the meridional winds at all local times, this picture now requires that at some local times the poleward strength of the meridional winds is decreased only slightly, while at others the circulation is reversed. In particular, we have shown that in the afternoon there is relatively little $(-20$ $\mathrm{m} / \mathrm{s}$ at most) change in the meridional circulation, or for that matter in the zonal circulation.

The consequences of the circulation and thermal changes on composition become much more understandable if constant pressure surfaces are used instead of constant height surfaces. When pressure surfaces are used, $\mathrm{O} / \mathrm{N}_{2}$ ratios increase at low- to middle-latitudes in the winter hemisphere in all cases, but decrease at high latitudes.

We have also shown that, in the simulation used here, there is a very strong correlation between storm-induced changes in neutral composition on a constant pressure surface and storm-induced changes in electron densities at the $F_{2}$ peak in the low-middle latitudes of the winter hemisphere. To explain this requires some background discussion of the relationship between the $\mathrm{O} / \mathrm{N}_{2}$ ratio and electron densities in the $F$ region.

During quiet geomagnetic times there is expected to be a correlation between the $\mathrm{O} / \mathrm{N}_{2}$ ratio and electron densities in the daytime if transport effects are removed. This is because ionization in the upper thermosphere results primarily from EUV radiation ionizing $O$, while ionization is lost due to the dissociative recombination of the $\mathrm{O}+$ ions with $\mathrm{N}_{2}$ and $\mathrm{O}_{2}$. Thus if the $\mathrm{O}_{2}$ is assumed to behave similarly to the $\mathrm{N}_{2}$, the $\mathrm{O} / \mathrm{N}_{2}$ ratio should be a good proxy for the electron content at any point. After dark there is no solar EUV radiation present, so, again ignoring any transport effects apart from the corotation of the ion flux tube with the Earth, the $\mathrm{O}+$ continuity equation is reduced to an exponential decay such that electron densities decay as (again assuming that the $\mathrm{O}_{2}$ densities behave in a similar manner to the $\mathrm{N}_{2}$ densities):

$$
\exp \left(-\int n\left(N_{2}\right) d t\right)
$$

Thus if we ignore transport effects, the $F$ region electron density at any point during the daytime will be dependent on the neutral composition at that point. At night the electron density will be dependent both on the density of the molecular neutral species and the residence time of the flux tube on the nightside.

These mechanisms can be used to determine whether changes in neutral composition can cause the positive storm effects in electron density. Previously, in assessing the importance of the neutral composition changes, either empirical and semiempirical models (which have been developed by using constant height surfaces) have been used, or it has been tacitly assumed that the electron densities respond to changes in composition on constant height surfaces (however, see Prölss [1987] for a consideration of constant pressure surfaces). But, as we showed in section 5 , the low- to middle-latitude, neutral composition changes in the winter hemisphere during geomagnetic storms were very different depending on whether constant pressure or constant height coordinates were used. The question then arises: should constant height surfaces or constant pressure surfaces reflect changes in $F_{2}$ peak electron densities better?

Rishbeth and Edwards [1989; 1990] addressed this problem during quiet geomagnetic times and concluded that electron densities at any particular local time are far better ordered on constant pressure surfaces than on constant height surfaces. This follows quite logically if the $\mathrm{O}+$ continuity equation is considered and transport effects are ignored. The height of the $F_{2}$ peak represents to the first order a balance between the ionization of atomic oxygen (which is in turn dependent on the density of $O$ ) and the recombination term that is dependent primarily on the density of the molecular species (see Rishbeth and Edwards [1989] for more details). If thermal expansion occurs, the density of all species increases at a constant height, as we showed in section 5 . Thus the balance height cannot be maintained on a constant height surface. However, the real height of a pressure surface increases because of thermal expansion, so, to a first approximation, the balance is maintained on a constant pressure surface.

Because the thermosphere heats up at low-middle latitudes during geomagnetic storms, the real heights of constant pressure surfaces will rise, and the balance point will also rise with them. Consequently, the height of the $F_{2}$ peak will also rise (the increases in altitude of the constant pressure surfaces are anywhere from 20 to $80 \mathrm{~km}$ in the low-middle latitudes). Thus to assess the importance of neutral composition to the increase of electron densities at low- to middle-latitudes of the winter hemisphere during a geomagnetic storm, constant pressure surfaces should be used, not constant height surfaces.

In section 6 our model results showed that there was a good correlation between the increases in the $\mathrm{O} / \mathrm{N}_{2}$ ratio on a constant pressure surface and increases in electron densities at the $F_{2}$ peak during the daytime at low-middle latitudes in the 
winter hemisphere. Furthermore, we showed in section 5 that although the size of the increases in the $\mathrm{O} / \mathrm{N}_{2}$ ratio in the TIGCM are larger than they are in the data, the behavior of the $\mathrm{O} / \mathrm{N}_{2}$ ratio in the model is in general agreement with that derived from the compositional data measured by the DE 2 satellite. Thus it is reasonable to assume that increases in neutral composition on a constant pressure surface are a major cause of the enhancements in electron density at the $F_{2}$ peak that have been observed in the low-to middle-latitudes of the winter hemisphere and at similar latitudes during equinoxes. At night this correlation is not quite as close because electron densities are dependent not only on the density of the molecular species, but also on the amount of time that a flux tube has not been sunlit.

We could not confirm these results by making direct comparisons between satellite-derived composition and electron density data because of the difficulties involved in reducing the electron density data to a set of constant pressures. Because the satellite is measuring electron densities at constant heights, it will sample a different part of the $F_{2}$ layer in storm time from the part sampled at quiet time. Without arbitrarily assuming an electron density distribution with height, it is impossible to adjust the satellite-derived electron densities for changes in the altitude of the $F_{2}$ peak, so normally, a comparison between satellite electron densities is not expected to yield any useful results (however, see Burns et al. [1995]).

Thus we do not present any electron density data in this paper. The only unambiguous source for such data is groundbased (primarily ionosonde) measurements. Electron densities during the December 7 and 8 storm were investigated by using ionosonde data by Prölss et al. [1991]. Among other results they built up a map of the regions in which positive storm effects occurred. These regions correlated well with the regions of positive storm effects calculated by the NCAR-TIGCM here. In addition, Prölss et al. presented a number of comparisons between "normal" quiet time electron densities and storm time electron densities for both December 7 and 8, 1982. In general, storm time electron densities seemed to be enhanced by about $15-20 \%$ in the late afternoon local time in the lowto middle-latitude winter hemisphere on December 8 . This enhancement is consistent with our observations that $\mathrm{O} / \mathrm{N}_{2}$ ratios on a constant pressure surface increased by about $20 \%$ between storm and quiet time orbits in this location at this time.

At first sight there is little difference between the effects of changes in the meridional winds on the low- to middlelatitude ionosphere in winter and the somewhat more complex mechanism discussed here. Both would result in increases in electron density at the $F_{2}$ peak, the thickening of the $F_{2}$ layer, and an increase in the total electron content. Similarly, the changes in neutral temperature that have been observed are explained by changes in the neutral winds, and, consequently in compressional heating and temperature. The increased temperature would then cause increases in the density of all neutral species on constant height surfaces. However, it is at this point that problems arise with the interpretation of the changes in electron density being driven directly by changes in the neutral circulation. Rishbeth and Edwards [1989; 1990] showed that $h_{m} F_{2}$ is tied more closely to constant pressure surfaces than to constant height surfaces. But, as we have shown here, the changes in neutral circulation that cause neutral temperature increases also result in noticeable changes in neutral composition on a constant pressure surface. These must be figured into any calculation of the changes in electron densities that may be caused by changing neutral winds.
Perhaps even more important in determining the effects of wind changes on electron densities is the three-dimensional morphology of the wind changes themselves. We have shown that there is little change in the meridional wind in the late afternoon during the long-term changes induced by geomagnetic storms. Yet there is sufficient evidence that increases in electron density occur in this region that are at least as large as those that are seen just after dawn [e.g., Prölss et al., 1991, and the references therein], when the increase in the equatorward component of the neutral wind is much greater. This presents problems if it is assumed that the meridional winds cause positive storm effects by driving electrons up field lines into regions where recombination is slower. No such problem arises when the less direct mechanism that has been discussed in this paper is invoked.

Mendillo et al. [1992] considered the role of the various processes (those discussed by Prölss et al. [1991]) in determining the causes of ionospheric composition changes. They used the MSIS model to characterize the neutral thermosphere. Because they did not show the increase in electron density due to compositional effects at low latitudes that are indicated by using the DE 2 data, it is likely that MSIS is not representing the compositional and thermal changes that occur at low latitudes during geomagnetic storms. Without an accurate representation of these changes, the derivation of the neutral wind from a servo model becomes problematic.

Our present work on electron densities that was done with the TIGCM is somewhat limited by a similar problem. The TIGCM overestimates the neutral composition effect in comparison with the DE 2 data, so we cannot be certain that the correlation between increases in $\mathrm{O} / \mathrm{N}_{2}$ ratio with electron density in the model output would continue to hold if the compositional changes in the model were the same as those in the data. However, there are indications from our results for neutral composition and the Prölss et al. [1991] calculations of the electron density changes during the same storm that the increases of electron densities at the $F_{2}$ peak are of the same order as the increases in $\mathrm{O} / \mathrm{N}_{2}$ ratio on a constant pressure surface, and that the geographical extent of these changes is similar. We intend to perform similar studies in the future with the TIEGCM to see whether the interactive dynamo affects the changes in low-latitude neutral composition strongly enough to cause the differences between the model and the data that were seen in this paper. We also intend to use the model to perform an estimate, similar to that of Mendillo et al. [1992], of the importance of the various terms in the ion continuity equation in the $F_{2}$ region.

The present study has considered only the longer-term changes in neutral composition that result from the changes in neutral circulation caused by a geomagnetic storm. A later study will consider the complicated interactions that are caused by the transient waves that are set up at the beginning of a geomagnetic storm. We also plan to undertake another study, using the NCAR-TIGCM, that involves a term analysis of the ion continuity equation.

\section{Conclusions}

We have studied DE 2 temperature and composition data and NCAR-TIGCM results and concluded the following:

1. The winds associated with the diurnal tide weaken during geomagnetic storms, causing primarily zonally oriented changes in the evening sector, small changes in the middle of the afternoon, a combination of zonal and meridional changes in the late morning region, and mainly meridional changes early in the morning. 
2. There is a small region in the late morning sector where changes in ion drag cause wind changes, but the main cause of these wind changes is the decrease in the normal dayto-night and winter-to-summer pressure gradients.

3. Reductions in the amplitude of the poleward component of the tidal wind (in the winter hemisphere morning sector in particular) result in decreases in the amount of energy advection out of the region of maximum solar heating in the low- to middle-latitude daytime. Consequently, temperatures increase throughout the winter low- to middlelatitude region during geomagnetic storms.

4. Decreased horizontal divergence results in weaker upward winds blowing through a constant pressure surface. Thus cooling through expansion, which is normally a major cooling mechanism in the afternoon, decreases. Similarly, compressional heating increases at night. The other heating and cooling processes change little except for some local effects, so the net result of the changes in the compression and expansion term is that the thermosphere is heated by $50-200$ $\mathrm{K}$ at low- to middle-latitudes. The size of the temperature increase varies with the local time of the observations and the size of the storm. These low- to middle-latitude temperature increases occur purely as a result of changes in neutral circulation caused by the effect of the high-latitude heat source; no extra low- to middle-latitude energy source is needed to explain the observed temperature increases shown here.

5. Changing vertical winds and temperatures also affect neutral composition and densities in winter at low-middle latitudes. For example, increased temperatures result in pressure surfaces that are higher than normal. If all else was equal, $\mathrm{N}_{2} / \mathrm{O}$ ratios should increase on constant height surfaces as a result of this rise. However, because the upward vertical winds through pressure surfaces are weaker, less nitrogen-rich air is advected upward and $\mathrm{N}_{2} / \mathrm{O}$ ratios decrease on constant pressure surfaces. These changes tend to cancel themselves out in terms of composition changes on constant height surfaces, although the densities of all individual species are higher.

6. Modeled increases in the $\mathrm{O} / \mathrm{N}_{2}$ ratio (decreases in $\mathrm{N}_{2} / \mathrm{O}$ ratio) on a constant pressure surface correlate strongly with modeled long-term positive storm effects in electron density.

Acknowledgments. This study was supported by NASA grants NAGW 3457 and NAG5-465 and by NSF grants ATM-8918476 and ATM 9400877 to the University of Michigan. The authors are grateful to $\mathrm{N}$. W. Spencer for providing DE 2 data. We also wish to acknowledge the National Center for Atmospheric Research, sponsored by NSF, for the computing time used in this research.

The Editor thanks M. Mendillo and G. W. Prölss for their assistance in evaluating this paper.

\section{References}

Appleton, E. V., and L. J. Ingram, Magnetic storms and upper atmospheric ionization, Nature, 136, 548-549, 1935.

Berkner, L. V., and S. L. Seaton, Systematic ionospheric changes associated with magnetic disturbances, J. Geophys. Res., 45, 419$423,1940$.

Berkner, L. V., H. W. Wells, and S. L. Seaton, Ionospheric effects associated with magnetic disturbances, J. Geophys. Res., 44, 283311,1939

Biondi, M. A., and J. W. Meriwether Jr., Measured response of the equatorial thermospheric temperature to geomagnetic activity and solar flux change, Geophys. Res. Letr., 12, 267-270, 1985.

Biondi, M. A., and D. P. Sipler, Studies of equatorial $630.0 \mathrm{~nm}$ airglow enhancements produced by a chemical release in the $F$ - region, Planet. Space Sci., 32, 1605-1610, 1985.
Blamont, J. E., and J. M. Luton, Geomagnetic effect on the neutral temperature of the $F$ region during the geomagnetic storm of September 1969, J. Geophys. Res., 77, 3534-3556, 1972.

Buonsanto, M. J., M. Mendillo, and J. A. Klobuchar, The ionosphere at $L=4$ : average behavior and the response to geomagnetic storms, Ann. Geophys., 35, 15-26, 1979.

Burns, A. G., and T. L. Killeen, The equatorial neutral thermospheric response to geomagnetic forcing, Geophys. Res. Lett., 19, 977-981, 1992a.

Burns, A. G., and T. L. Killeen, Changes of neutral composition in the thermosphere, Adv. Astronaut. Sci., 3, 2295-2312, $1992 \mathrm{~b}$.

Burns, A. G., T. L. Killeen, and R. G. Roble, Causes of changes in composition calculated using a thermospheric general circulation model, J. Geophys. Res., 94, 3670-3686, 1989.

Burns, A. G., T. L. Killeen, and R. G. Roble, A simulation of thermospheric composition changes during an impulse storm, $J$. Geophys. Res., 96, 14153-14167, 1991.

Burns, A. G., T. L. Killeen, and R. G. Roble, A simulation of the thermospheric composition changes seen during a geomagnetic storm, Adv. Space Res., I2(10), 253-256, 1992 a.

Burns, A. G., T. L. Killeen, and R. G. Roble, Thermospheric heating away from the auroral oval during geomagnetic storms, Can. $J$. Phys., 70, 544-551, $1992 \mathrm{~b}$.

Burns, A. G., T. L. Killeen, G. R. Carignan, and R. G. Roble, Large enhancement in the $\mathrm{O} / \mathrm{N}_{2}$ ratio in the evening sector of the winter hemisphere during geomagnetic storms, J. Geophys. Res., in press, 1995.

Burrage, M. D., V. J. Abreu, N. Orsini, C. G. Fesen, and R. G. Roble, Geomagnetic activity effects on the equatorial neutral thermosphere, J. Geophys. Res., 97, 4177-4187, 1992.

Cannata, R. W., T. L. Killeen, T. I. Gombosi, A. G. Burns, and R. G. Roble, Modelling of time-dependent ion outflows at high geomagnetic latitudes, Adv. Space Res., 8, 89-92, 1988.

Carignan, G. R., B. P. Block, J. C. Maurer, A. E. Hedin, C. A. Reber, and N. W. Spencer, The neutral mass spectrometer on Dynamics Explorer, Space Sci. Instrum., 5, 429-441, 1981.

Carlson, H. C., and G. Crowley, The equinox transition study: an overview, J. Geophys. Res., 94, 16861-16868, 1989.

Chandra, S., and N. W. Spencer, Thermospheric storms and related ionospheric effects, J. Geophys. Res., 8I, 5018-5026, 1976.

Crowley, G., B. A. Emery, R. G. Roble, H. C. Carlson Jr., and D. J. Knipp, Thermospheric dynamics during September 18-19, 1984, 1. Model simulations, J. Geophys. Res., 94, 16925-16944, 1989.

Deng, W., T. L. Killeen, A. G. Burns, and R. G. Roble, The flywheel effect: ionospheric currents after a geomagnetic storm, Geophys. Res. Lett., 18, 1845-1849, 1991.

Deng, W., T. L. Killeen, A. G. Burns, R. G. Roble, J. Slavin, and L. E. Wharton, The effects of neutral inertia on ionospheric currents in the high-latitude thermosphere following a geomagnetic storm, J. Geophys. Res., 98, 7775-7790, 1993.

Dickinson, R. E., E. C. Ridley, and R. G. Roble, A three-dimensional general circulation model of the thermosphere, J. Geophys. Res., 86, $1499-1512,1981$.

Dickinson, R. E., E. C. Ridley, and R. G. Roble, Thermospheric general circulation with coupled dynamics and composition, J. Atmos. Sci., 4I, 205-219, 1984.

Duncan, R. A., $F$-region seasonal and magnetic-storm behaviour, $J$. Atmos. Terr. Phys., 31, 59-70, 1969.

Forbes, J. M., Evidence for the equatorward penetration of electric fields, winds, and compositional effects in the Asian/Pacific sector during the September 17-24, 1984, ETS interval, J. Geophys. Res., 94, 16,999-17,008, 1989

Forbes, J. M., R. G. Roble, and F. A. Marcos, Thermospheric dynamics during the March 22, 1979, magnetic storm, 2. Comparisons of model predictions with observations, J. Geophys. Res., 92, 6069-6081, 1987.

Fuller-Rowell, T. J., and D. Rees, A three-dimensional time-dependent global model of the thermosphere, J. Atmos. Sci., 37, 2545-2567, 1980.

Fuller-Rowell, T. J., and D. Rees, A three-dimensional time dependent simulation of the global dynamical response of the thermosphere to a geomagnetic substorm, J. Atmos. Terr. Phys., 43, 701-721, 1981. 
Fuller-Rowell, T. J., and D. Rees, Derivation of a conservation equation for mean molecular weight for a two-constituent gas within a threedimensional, time-dependent model of the thermosphere, Planet. Space Sci., 3I, 1209-1222, 1983.

Fuller-Rowell, T. J., S. Quegan, D. Rees, R. J. Moffett, and G. J. Bailey, Interactions between neutral thermospheric composition and the polar ionosphere using a coupled ionosphere-thermosphere model, $J$. Geophys. Res., 92, 7744-7748, 1987.

Fuller-Rowell, T. J., D. Rees, B. A. Tinsley, H. Rishbeth, A. S. Rodger, and $S$. Quegan, Modelling the response of the thermosphere and ionosphere to geomagnetic storms: effects of a mid-latitude heat source, Adv. Space Res., IO(6), 215-224, 1989

Fuller-Rowell, T. J., D. Rees, H. Rishbeth, A. G. Burns, T. L. Killeen, and R. G. Roble, The composition change theory of F-region storms: a reassessment, J. Atmos. Terr. Phys., 53, 797-815, 1991

Fuller-Rowell, T. J., M. V. Codrescu, R. J. Moffett, and S. Quegan, Response of the thermosphere and ionosphere to geomagnetic storms, J. Geophys Res., 99, 3893-3914, 1994.

Hargreaves, J. K., and F. Bagenal, The behavior of the electron content during ionospheric storms: a new method of presentation and comments on the positive phase, J. Geophys. Res., 82, 731-733, 1977.

Hays, P. B., T. L. Killeen, and B. C. Kennedy, The Fabry-Perot interferometer on Dynamics Explorer, Space Sci. Instrum., 5, 395$416,1981$.

Hedin, A. E., P. Bauer, H. G. Mayr, G. R. Carignan, L. H. Brace, H. C. Brinton, A. D. Parks and D. T. Pelz, Observations of neutral composition and related ionospheric variations during a magnetic storm in February 1974, J. Geophys. Res., 82, 3183-3189, 1977.

Hedin, A. E. et al., Revised global model of thermosphere winds using satellite and ground based observations, J. Geophys. Res., 96, 76577688, 1991.

Hoffman, R. A., G. D. Hogan, and R. C. Maehl, Dynamics Explorer spacecraft and ground operations system, Space Sci. Instrum., 5 , 349-367, 1981.

Jakowski, N., E. Putz, and P. Spalla, Ionospheric storm characteristics deduced from satellite radio beacon observations at three European stations, Ann. Geophys., 8, 343-352, 1990.

Killeen, T. L., and R. G. Roble, An analysis of the high latitude thermospheric wind pattern calculated by a thermospheric general circulation model, J. Geophys. Res., 89, 7509-7522, 1984.

Killeen, T. L., and R. G. Roble, Neutral parcel transport in the high latitude F-region, in The Polar Cusp, edited by J. A. Holtet and A Egeland, pp. 261-278, D. Reidel, Norwell, Mass., 1985.

Killeen, T. L., and R. G. Roble, An analysis of the high-latitude thermospheric wind pattern calculated by a thermospheric general circulation model, 2, Neutral parcel transport, J. Geophys. Res., 91, 11,291-11,307, 1986.

Killeen, T. L., P. B. Hays, G. R. Carignan, R. A. Heelis, W. B. Hanson, N. W. Spencer, and L. H. Brace, lon-neutral coupling in the high latitude $F$ region: Evaluation of ion heating terms from Dynamics Explorer 2, J. Geophys. Res., 89, 7495-7508, 1984.

McCormac, F. G., T. L. Killeen, J. P. Thayer, C. R. Tschan, G Hernandez, J. J. Ponthieu, and N. W. Spencer, Circulation of the polar thermosphere during geomagnetically active and quiet times as observed from DE 2, J. Geophys. Res., 92, 10,133-10,139, 1987.

Mayr, H. G., I. Harris, and N. W. Spencer, Some properties of upper atmosphere dynamics, Rev. Geophys., 16, 539-565, 1978.

Mayr, H. G., I. Harris, F. Varosi and F. A. Herrero, Global excitation of wave phenomena in a dissipative multiconstituent medium, 2, Impulsive perturbations in the Earth's thermosphere, J. Geophys. Res., 89, 10,961-10,986, 1984.

Mendillo, M., X.-Q. He, and H. Rishbeth, How the effects of winds and electric fields in $F 2$ layer storms vary with latitude and longitude: a theoretical study, Planet. Space Sci., 40, 595-606, 1992.

Nisbet, J. S., B. J. Wydra, C. A. Reber, and J. M. Luton, Global exospheric temperatures and densities under active solar conditions, Planet. Space Sci., 24, 61-67, 1977.

Prölss, G. W., Magnetic storm associated perturbation of the upper atmosphere: recent results obtained by satellite-borne gas analyzers, Rev. Geophys., 18, 183-202, 1980.

Prölss, G. W., Latitudinal structure and extension of the polar atmospheric disturbance, J. Geophys. Res., 86, 2385-2396, 1981.
Prölss, G. W., Storm-induced changes in the thermospheric composition at middle latitudes, Planet. Space Sci., 35, 807-811, 1987.

Prölss, G. W., On explaining the local time variation of ionospheric storm effects, Ann. Geophys., 11, 1-9, 1993.

Prölss, G. W., M. Roemer, and J. W. Slowey, Dissipation of solar wind energy in the earth's upper atmosphere: the geomagnetic activity effect, Adv. Space Res., 8, 5/6, 215-261, 1988.

Prölss, G. W., L. H. Brace, H. G. Mayr, G. R. Carignan, T. L. Killeen, and J. A. Klobuchar, Ionospheric storm effects at subauroral latitudes: a case study, J. Geophys. Res., 96, 1275-1288, 1991.

Reiff, P. H., and J. G. Luhmann, Solar wind control of the polar-cap voltage, in Solar Wind-Magnetosphere Coupling, edited by $\mathrm{Y}$. Kamide and J. A. Slavin, pp. 453-476, Terra Scientific Publishing Company, Tokyo, Japan, 1986

Reiff, P. H., R. W. Spiro, R. A. Wolf, Y. Kamide, and J. H. King, Comparison of polar cap potential drops estimated from solar wind and ground magnetometer data: CDAW 6, J. Geophys. Res., 90, 1318-1324, 1985.

Richmond, A. D., E. C. Ridley, and R. G. Roble, A thermosphere/ionosphere general circulation model with coupled electrodynamics, Geophys. Res. Lett., 19, 601-604, 1992.

Rishbeth, H., On the $F 2$-layer continuity equation, J. Atmos. Terr. Phys, $48,511-519,1986$

Rishbeth, H., and R. Edwards, The isobaric F2-layer, J. Atmos. Terr. Phys., 51, 321-338, 1989.

Rishbeth, H., and R. Edwards, Modeling the F2 layer peak height in terms of atmospheric pressure, Radio Sci., 25, 757-769, 1990.

Rishbeth, H., S. Ganguly, and J. C. G. Walker, Field-aligned and fieldperpendicular velocities in the ionospheric F2-layer, J. Atmos. Terr. Phys., 40, 767, 1978.

Rishbeth, H., R. Gordon, D. Rees, and T. J. Fuller-Rowell, Modelling of thermospheric composition changes caused by a severe magnetic storm, Planet. Space Sci., 33, 1283-1301, 1985.

Rishbeth, H., T. J. Fuller-Rowell, and A. S. Rodger, $F$-layer storms and thermospheric composition, Phys. Scr., 36, 327-336, 1987.

Roble, R. G., Chemistry in the thermosphere and ionosphere, Chem Eng. News, 64(24), 23-38, 1986.

Roble, R. G., and E. C. Ridley, A thermosphere-ionospheremesosphere-electrodynamics general circulation model (time-GCM): equinox solar cycle minimum simulations $(30-500 \mathrm{~km})$, Geophys. Res. Lett., 21, 417,420, 1994.

Roble, R. G., R. E. Dickinson, and E. C. Ridley, Global circulation and temperature structure of thermosphere with high-latitude plasma convection, J. Geophys. Res., 87, 1599-1614, 1982.

Roble, R. G., E. C. Ridley, and R. E. Dickinson, On the global mean structure of the thermosphere, J. Geophys. Res., 92, 8745-8758, $1987 \mathrm{a}$.

Roble, R. G., J. M. Forbes, and F. A. Marcos, Thermospheric dynamics during the March 22, 1979, magnetic storm, 1, model simulations, $J$. Geophys. Res., 92, 6045-6068, $1987 \mathrm{~b}$.

Roble, R. G., E. C. Ridley, A. D. Richmond, and R. E. Dickinson, A coupled thermosphere/ionosphere general circulation model, Geophys. Res. Lett., 15, 1325-1328, 1988.

Seaton, M. J., A possible explanation of the drop in $F$-region critical densities accompanying major ionospheric storms, J. Atmos. Terr. Phys., 8, 122-124, 1956.

Spencer, N. W., L. E. Wharton, H. B. Niemann, A. E. Hedin, G. R. Carignan, and J. C. Maurer, The Dynamics Explorer wind and temperature spectrometer, Space Sci. Instrum., 5, 417-428, 1981

Taeusch, D. R., G. R. Carignan, and C. A. Reber, Neutral composition variation above $400 \mathrm{~km}$ during a magnetic storm, J. Geophys. Res., $76,8318-8325,1971$

A. G. Burns, G. R. Carignan, W. Deng, and T. L. Killeen, Space Physics Research Laboratory, Department of Atmospheric, Oceanic and Space Sciences, The University of Michigan, Ann Arbor, MI 48109-2143. (e-mail: aburns@gandalf.engin.umich.edu)

R. G. Roble, National Center for Atmospheric Research, P.O. Box 3000 , Boulder, CO 80307.

(Received September 21, 1994; revised December 2, 1994; accepted December 2, 1994.) 
